\title{
Predictors of long-term change in adult cognitive performance: systematic review and data from the Northern Finland Birth Cohort 1966
}

\section{Predictors of change in cognitive ability}

Irina Rannikko ${ }^{\mathrm{a}^{*}, \mathrm{~b}^{*}}$, Erika Jääskeläinen ${ }^{\mathrm{b}, \mathrm{c}}$, Jouko Miettunen ${ }^{\mathrm{b}, \mathrm{c}}$, Anthony O. Ahmed $^{\mathrm{d}}$, Juha Veijola ${ }^{\mathrm{a}, \mathrm{b}, \mathrm{e}}$, Anne M Remes ${ }^{\mathrm{f}}$, Graham K Murray ${ }^{\mathrm{g}, \mathrm{h}}$, Anja P. Husa $^{\mathrm{a}, \mathrm{b}, \mathrm{e}}$, Marjo-Riitta Järvelin ${ }^{\mathrm{c}, \mathrm{i}, \mathrm{j}, \mathrm{k}, \mathrm{l}}$, Matti Isohanni ${ }^{\mathrm{a}, \mathrm{e}}$, Marianne Haapea ${ }^{\mathrm{b}, \mathrm{c}, \mathrm{e}, \mathrm{m}}$

${ }^{a}$ Center for Clinical Neurosciences, Department of Psychiatry, P.O. Box 5000, 90014 University of Oulu, Finland

${ }^{b}$ Medical Research Center Oulu, Oulu University Hospital and University of Oulu, Oulu, Finland

${ }^{c}$ Center for Life Course Health Research, P.O.BOX 5000, FIN-90014 University of Oulu, Finland.

${ }^{d}$ Department of Psychiatry, Weill Cornell Medical College, 21 Bloomingdale Road, White Plains, NY 10605 USA

e Oulu University Hospital, Department of Psychiatry, P.O. Box 26, FIN-90029, OYS, Finland

${ }^{f}$ Institute of Clinical Medicine - Neurology, University of Eastern Finland, Kuopio, Finland; Department of Neurology, Kuopio University Hospital, Kuopio, Finland

${ }^{g}$ University of Cambridge, Department of Psychiatry, Box 189 Addenbrooke's Hospital, Cambridge CB2 OQQ United Kingdom.

${ }^{h}$ University of Cambridge, Behavioural and Clinical Neuroscience Institute, Herchel Smith Building, Forvie Site, Cambridge Biomedical Campus, Cambridge CB2 OSZ, UK

${ }^{i}$ Department of Epidemiology and Biostatistics, MRC Health Protection Agency (HPA) Centre for Environment and Health, School of Public Health, Imperial College London, UK

${ }^{j}$ Biocenter Oulu, P.O.Box 5000, Aapistie 5A, FI-90014 University of Oulu, Finland 
${ }^{k}$ Unit of Primary Care, Oulu University Hospital, Kajaanintie 50, P.O.Box 20, FI-90220 Oulu, 90029 OYS, Finland

${ }^{l}$ Department of Children and Young People and Families, National Institute for Health and Welfare, Aapistie 1, Box 310, FI-90101 Oulu, Finland

${ }^{m}$ Oulu University Hospital, Department of Diagnostic Radiology, P.O. Box 50, FIN-90029, OYS, Finland. 
* M. Psych., PhD student Irina Rannikko, Center for Clinical Neurosciences, Department of Psychiatry, P.O. Box 5000, 90014 University of Oulu, Finland. Tel. + 358405393199 , Email address: $\underline{\text { irina@ rannikko.org }}$

Co-authors:

MD, PhD Erika Jääskeläinen, Center for Life Course Health Research, P.O.BOX 5000, FIN90014 University of Oulu, Finland. Tel. +358 407474376.

Email address: erika.jaaskelainen@oulu.fi

PhD Jouko Miettunen, Center for Life Course Health Research, P.O.BOX 5000, FIN-90014 University of Oulu, Finland. Tel. + 3588315 6923. Email address: jouko.miettunen@ oulu.fi

PhD Anthony O. Ahmed, Department of Psychiatry, Weill Cornell Medical College, 21

Bloomingdale Road, White Plains, NY 10605, USA. Tel. 09-1-914-997-5251

Email: aoa9001@med.cornell.edu

MD, PhD Juha Veijola, Center for Clinical Neurosciences, Department of Psychiatry, P.O.

Box 5000, 90014 University of Oulu, Finland. Tel. + 35883156910.

Email address: juha.veijola@oulu.fi

MD, PhD Anne M Remes, Institute of Clinical Medicine - Neurology, University of Eastern Finland, P.O. Box 1627, FI-70211 Kuopio, Finland. Tel. + 358403552014.

Email address: anne.remes@uef.fi

MD, PhD Graham K Murray, University of Cambridge, Department of Psychiatry, Box 189, Addenbrooke's Hospital, Cambridge CB2 2QQ UK. Tel. + 44-0-1223-764678.

Email address: gm285@cam.ac.uk

MD, PhD student Anja P. Husa, Center for Clinical Neurosciences, Department of Psychiatry, P.O. Box 5000, 90014 University of Oulu, Finland. Tel. + 35883156910. Email address: anja.husa@student.oulu.fi

MD, PhD Marjo-Riitta Järvelin, Institute of Health Sciences, Center for Life Course Epidemiology and Systems. Tel. + 358294485659.

Email address: m.jarvelin@imperial.ac.uk 
MD, PhD Matti Isohanni, Center for Clinical Neurosciences, Department of Psychiatry, P.O. Box 5000, 90014 University of Oulu, Finland. Tel. + 35883156910.

Email address: matti.isohanni@oulu.fi

PhD Marianne Haapea, Center for Life Course Health Research, P.O.BOX 5000, FIN-90014 University of Oulu, Finland. Tel. + 3588315 6910. Email address:

marianne.haapea@oulu.fi 


\section{ABSTRACT}

Objective: Several social life events and challenges have an impact on cognitive development. Our goal was to analyse the predictors of change in cognitive performance in early midlife in a general population sample. Additionally, systematic literature review was performed.

Method: The study sample was drawn from the Northern Finland Birth Cohort 1966 at the ages of 34 and 43 years. Primary school performance, sociodemographic factors and body mass index (BMI) were used to predict change in cognitive performance measured by the California Verbal Learning Test, Visual Object Learning Test, and Abstraction Inhibition and Working Memory task. Analyses were weighted by gender and education, and p-values were corrected for multiple comparisons using BenjaminiHochberg procedure (B-H).

Results: Male gender predicted decrease in episodic memory. Poor school marks of practical subjects, having no children, and increase in BMI were associated with decrease in episodic memory, though non-significantly after B-H. Better school marks, and higher occupational class were associated with preserved performance in visual object learning. Higher vocational education predicted preserved performance in visual object learning test, though non-significantly after B-H. Likewise, having children predicted decreased performance in executive functioning but non-significantly after B-H.

Conclusions: Adolescent cognitive ability, change in BMI and several sociodemographic factors appear to predict cognitive changes in early midlife. The key advantage of present study is the exploration of possible predictors of change in cognitive performance among general population in the early midlife, a developmental period that has been earlier overlooked.

Keywords: Predictor; Cognitive ability; Follow-up; Middle age; Birth cohort. 


\section{INTRODUCTION}

\section{Review of the literature}

Change of cognitive ability during life is gradual, suggesting that the cognitive changes may be an ordinary developmental process. Some prospective studies have demonstrated that cognitive performance increases with age through childhood and adolescence (e.g. Anderson, Anderson, Northam, Jacobs, \& Catroppa, 2001; Korkman, Kemp, \& Kirk, 2001). Cognitive performance increases up until the third or fourth decade of life (Clark et al., 2006) with higher levels of vocational education and contribution of gender effects on measures of cognitive functioning. Also, many studies have demonstrated evidences of age- and education-related gradual decline of cognitive performance in the fifth decade and beyond (e.g. Colsher \& Wallace, 1991; Hahn \& Lachman, 2015; Richards et al., 2014; Schaie, 1994; Tomaszewski Farias et al., 2011; Zelinski \& Burnight, 1997).

Early midlife is a crucial period of the person's life cycle with the key social everyday life challenges that have major influences on cognitive development. Although there is emerging information available about the age of onset of cognitive change and risk factors of cognitive decline, there remains a gap in the literature regarding studies of the factors and nature of cognitive change during early midlife.

In our previous nine-year follow-up study (Rannikko et al., 2015), we detected that cognitive decline occurred already in early midlife when participants were in their third and fourth decades of life. Also other earlier studies suggest, that age-related cognitive decline begins relatively early in adulthood (Cristensen, 2001; Salthouse, 2009; Sing-Manoux et al., 2012), 
but it seems to be still unclear which environmental and developmental factors may be associated with it (Ramscar, Hendrix, Shaoul, Milin, \& Baayen, 2014; Salthouse, 2009).

Many factors have been investigated as potential predictors of change in cognitive ability. A large body of literature has demonstrated that basic sociodemographic predictors, such as education, gender, and acculturation, and a variation of clinical and psychological factors can have strong influence on cognitive functioning in both, cross -sectional and longitudinal research. More specifically, higher education (Hultsch \& Dixon, 1984), being married and being employed associated with good cognitive functions (West, Crook, \& Barron, 1992); clinical conditions such as pain and hypertension (Piccini, Muniz, Sparks, \& Bontempo, 2011) and mid-life obesity (Cournot et al., 2006), and depression especially in older adults (Jorm, 1986) have been associated with poorer cognitive ability in later life (Kivipelto et al., 2001). Some longitudinal studies show faster age-related cognitive decline in those with poor education (Agrigoroaei and Lachman, 2011; Colsher and Wallace, 1991; Hahn and Lachman, 2015; Matthews et al., 2004; Nguyen et al., 2002; Osler et al., 2013; Richards et al., 2004; Schaie, 1994). Also poor self-ratings of health and physical activity predicted greater cognitive deterioration (Carmelli et al., 1997) and number of adaptive psychosocial and behavioral factors have been found to be positively associated with change in reasoning abilities (Agrigoroaei and Lachman, 2011).

There has recently been a growing interest in relationship between body composition and cognitive ability. Obesity-associated hypertension - an important risk factor of vascular disease (Kopelman, 2000) - can contribute to decline in cognitive function via the vascular pathway (Desmond, 2004). There is evidence of an association between higher body mass index (BMI) at baseline and decline in cognitive performance in healthy workers aged 32 to 62 years at baseline (Cournot et al., 2006). Obesity in middle age appears to increase the risk 
of late-life cognitive decline and dementia (Kivipelto et al., 2005). On the other hand some aging studies have found low weight loss to be associated with less cognitive decline (Sturman et al., 2008).

\section{Systematic literature search and review}

Understanding the factors associated with longitudinal change in cognitive performance in the early middle aged general population is important for the clarification of normative development processes in early midlife as well as etiological investigation of degenerative processes and for preventive purposes. However, there is a lack of studies with years of follow-up focusing on change in cognitive performance during lifetime period between the ages of 30 and 50 years. Furthermore, predictors of change in cognitive ability have been analysed mostly in older age groups, and very rarely in samples of the early middle age.

To summarise the results of previously studies of at least 5-years follow-up with different clinical or population-based cohort samples analysing predictors of longitudinal cognitive change, the systematic literature search was completed in August 2015 using electronic database PubMed and manual searches. The search produced 4525 results. Based on the information on abstracts, 84 articles were selected for comprehensive evaluation. 22 articles met our inclusion criteria and were included in the systematic review. A detailed description of the literature search procedure is presented in Figure 1.

Figure 1 about here

The included studies consisted of participants aged between 12 and 102 years. The studies administered several neuropsychological tests including the Mini-Mental State 
Examination (MMSE), the California Verbal Learning Test-I and II (CVLT-I and CVLT-II), the Wechsler Adult Intelligence Scale (WAIS), and the Benton Visual Retention Test.

Several predictors of change in cognitive ability have been examined including baseline basic demographic variables (age, gender, education), occupation-based social class, clinical characteristics (e.g. BMI, blood pressure) and psychological and behavioural factors. Among analyzed sociodemographic predictors, advanced age predicted decline in cognitive performance in eight studies. Gender was associated with decline in cognitive ability in two studies and lower educational level was associated with higher cognitive decline in eight studies. Marital status and social class predicted cognitive decline in two studies. Psychological factors were positively related to cognitive change in one study. Clinical conditions (BMI, blood pressure, diabetes) were associated with change in cognitive performance in four studies. Please, see Table 1 for details.

Table 1 about here

\section{Aims and hypotheses of the study}

Our aim was to provide novel information on factors predicting the change in cognitive ability between the ages of 34 and 43 years in individuals drawn from an unselected, epidemiologically sound general population sample. We analysed primary school performance at age 16 years, sociodemographic factors in adulthood and BMI and their associations with change in cognitive performance in early midlife. Our research hypotheses were that female gender, single marital status, parenthood, higher BMI, poorer primary school performance and vocational education, and lower occupational class would be associated with decline in cognitive ability. 


\section{METHOD}

\section{Participants}

The Northern Finland Birth Cohort 1966 study (NFBC 1966) is an unselected general population birth cohort ascertained during mid-pregnancy. The NFBC 1966 consist of 12058 live-born children in the provinces of Lapland and Oulu with an expected delivery date during 1966 (Rantakallio, 1988). There were 11017 eligible individuals in Finland at the age of 16 years. Of these, 83 individuals did not consent to the use of their data and have been excluded. The Ethical Committee of the Northern Ostrobothnia Hospital District has approved the study design of the NFBC 1966. The current study has been performed in accordance with the ethical standards laid down in the 1964 Declaration of Helsinki and its later amendments.

The baseline study was conducted in 1999-2001 (at age of approx. 34 years), with follow-up in 2008-2010 (at age of approx. 43 years). Participants were given a complete description of the study and had the opportunity to refuse participation. All participants provided written informed consent.

\section{Identification of the sample}

As part of the NFBC 1966 psychosis case-control study (Haapea et al., 2007; Husa et al., 2014; Veijola et al., 2014), a total of 187 (116 men (62\%)) randomly selected individuals without a known psychotic episode and living in the Oulu region were invited to participate in the baseline study. We used gender stratified random sampling, with the aim of recruiting a preponderance of men in this general population sample, as the sample had to serve as a comparison group in a psychosis study (Haapea et al., 2007). Of the 187 invited, 104 (56\%) participated. All participants in the baseline study were invited to participate in the follow-up, and $76(73 \%)$ of them participated. Neuropsychological tests (three cognitive measures), and diagnostic and health-related interviews were conducted at both baseline and follow-up 
studies (Husa et al., 2014; Kobayashi et al., 2014; Veijola et al., 2014). The present study is based on those 75 subjects (46 males and 29 females) for whom data on at least one of the three cognitive measures were available at both baseline and follow-up. The mean follow-up time was 8.5 (standard deviation 0.7 ) years.

The proportion of men in our sample was higher, though statistically nonsignificantly, than in the rest of the cohort (61\% vs. $51 \%, \mathrm{p}=0.082)$. There were no differences in primary school marks between the sample of this study and the rest of the cohort (Table 2). Our sample was, however, more educated by 1997 compared to the rest of the cohort (4.0\% vs. $15.1 \%$ with low, $64.0 \%$ vs. $59.5 \%$ with middle and $32.0 \%$ vs $25.4 \%$ with high education; $\mathrm{p}=0.021$ ). When compared to the baseline participants, who did not participate or had none of the cognitive measurements in the follow-up study, our sample did not differ in selected cognitive measures in baseline nor in gender or education (Table 2).

Table 2 about here

\section{Neuropsychological assessments}

All participants were assessed by trained investigators to be capable of providing informed consent. A neuropsychological battery at the baseline and follow-up included the California Verbal Learning Test (CVLT; Delis, Kramer, Kaplan, \& Ober, 1987), Visual Object Learning Test (VOLT; Glahn, Gur, Ragland, Censits, \& Gur, 1997) and the Abstraction, Inhibition and Working Memory task (AIM; Glahn, Cannon, Gur, Ragland, \& Gur, 2000).

\section{Verbal learning and memory}

The CVLT was administered and scored by trained examiners in a fixed order at age 34 and in exactly the same way at follow-up at age 43 . The CVLT was the only word-list 
memory task administered in a given neuropsychological test session to minimize possible interference effects between the tests.

The CVLT provides a brief, individually administered assessment of multiple strategies, processes, and errors involved in learning and remembering verbal material. The test measures both recall and recognition of word lists of 16 words over a number of trials and requires memorization of a word list consisting of items from four semantic categories, four words per category. The words are presented so that a given word is never followed by another word from the same category. The test evaluates a subject's ability to recall a word list in any order over five trials (Delis et al., 1987).

To describe the various domains of verbal learning and memory, the following seven measures of the CVLT were analysed: span of apprehension (possible range 0-16), immediate free recall (0-80), short delay free recall (0-32), long delay free recall (0-32), recognition discriminability (0-100), recall consistency (0-1) and intrusions (n.a.).

\section{Visual Object Learning and Memory}

The VOLT, a measure of visual-spatial learning and memory that was developed to examine aspects of visual-spatial learning and memory in a manner analogous to available verbal tests (e.g., CVLT). It is modelled after the CVLT, and the stimuli are complex and unfamiliar geometric designs that are unpronounceable. Like the CVLT, the VOLT has multiple learning trials, though the VOLT consists of four rather than five, followed by an interference list as well as short-delay and long-delay trials (Glahn et al., 1997). The VOLT uses Euclidean shapes as stimuli with the same paradigm as the word. Participants are showed a set of 10 visual objects -the learning set. In a forced choice paradigm, they are then required to recognize those stimuli within a group of 20 objects, of which 10 are distractors. After each trial, the learning set is presented. The dependent variable is the total number of correct 
responses in the four trials summed. The participant's score reflects the number of correctly recognized targets and correctly rejected foils. The procedure is repeated at 20 min delay. Two forms are available for each test. The VOLT score ranges from 0 to 80 points. The scores less than half of the maximum score (i.e. less than 40 points) are considered as below chance.

\section{Measure of Abstraction and Measure of Abstraction With Memory}

The AIM is a computerized rule-abstraction/category learning task that requires subjects to use information related to group stimuli in a meaningful way on the basis of feedback received during the test. In this task, manipulation of information is operationalized as visual abstraction. It is generally considered that abstraction and categorisation are executive functions. Two pairs of stimuli are presented on the top of the screen: one pair in the top left, and one in the top right. The stimuli can be of various colours and shapes. An additional stimulus - a target stimulus of variable shape and colour - is presented at the bottom center of the screen. The participant has to choose which pair of stimuli fits with the target stimulus. This target stimulus can match one or more of the four stimuli at the top of the screen across one or more dimensions in such a way that the target and one of the pairs form three objects in a set. This task yields two outcome measures: total score on the abstraction trials and total score on the trials involving abstraction with memory (Glahn et al., 2000). The scores range from 0 to 30 points. The scores less than half of the maximum score (i.e. less than 15 points) are considered as below chance.

To perform the task successfully one must be able to abstract information about shape and colour, and use this information to make category judgements on the basis of shared characteristics. The different combinations of shape and color were used to generate the stimuli sets. 


\section{Predictors of change in cognitive performance}

The following plausible predictors of change of cognitive performance were analysed:

Gender. Male, female.

Primary school marks at the age of 16 years were collected from the national register. In Finland, school marks range from 4 to 10 . Each set of marks is defined in the following way: 4 is rejected, 5-6 are poor, 7-8 are satisfactory and 9-10 are excellent. The mean scores of all subjects, and theoretical and practical subjects, separately, were calculated from the school reports at the end of compulsory primary school. The theoretical subjects are: native language, reading; native language, literal; second, third, fourth and fifth language; mathematics; chemistry; physics; history; biology; geography; religion and civics. The practical subjects are: physical education, music, drawing, craft, domestic science, commercial subjects, typewriting, and agriculture.

Educational level. Non-vocational education (comprehensive school, in total 9 years, or general upper secondary school, in total 12 years with matriculation examination) and vocational education (lower level: none, vocational course or school (up to 3 years in vocational institution), currently a student; or higher level: polytechnic or university) were enquired about in a questionnaire at 43 years of age. These were combined as a level of education: Low $=$ comprehensive school with a lower level of vocational education; middle = comprehensive school with a higher level of vocational education or upper secondary school with a lower level of vocational education; and high = upper secondary school with a higher level of vocational education.

Occupational class was ascertained by questionnaire at age 34 (high = managerial employee; middle $=$ official level employee; low = employee and others (students and unemployed). 
Marital status was ascertained by questionnaire at the baseline study (married/cohabiting, others).

Children Whether or not the subjects had children was ascertained by questionnaire at the baseline study (yes/no).

Body mass index (BMI) was calculated from self-reported height and weight. The BMI at the baseline study and the change of BMI between the baseline and follow-up were used in the analyses.

\section{Statistical analyses}

The sample was compared with the rest of the NFBC 1966 members in order to evaluate the representativeness of the sample and with the participants of the baseline study using chi square test for categorical (gender and educational level) and independent samples t-test for continuous (primary school marks and selected cognitive performance measures) variables. The characteristics of the sample are presented using frequency distributions and means with standard deviations. Cognitive performance at baseline and follow-up was compared using a paired samples t-test. Follow-up cognitive performance was standardized using the mean and standard deviation of the baseline cognitive performance to form the follow-up Z-score. The effect of the predictors to baseline cognitive performance was analysed using linear regression analysis, each predictor separately to each cognitive performance measure. To analyse the predictors of changes in CVLT, VOLT and AIM, linear regression analysis adjusted for the corresponding baseline cognitive performance, separately for each cognitive performance measure, was used in order to determine betas to express the effect sizes. The previous analyses were conducted using inverse probability weighting by gender and education in order to correct for their distribution in the sample. P-values are presented uncorrected for multiple comparisons. Additionally Benjamini-Hochberg (B-H) procedure was used to correct for multiple comparisons and B-H corrected p-values $\left(p_{B-H}\right)$ are 
given when uncorrected p-values showed statistical significance. For post hoc analyses means of follow-up Z-scores (separately for CVLT, VOLT and AIM) were used to classify the study sample into groups of high and low cognitive performance groups ('preserved or increased cognitive performance' $=$ the mean Z-scores of at least two measures of cognitive ability preserved or increased; 'decreased cognitive performance' $=$ the mean Z-scores of at least two measures of cognitive ability decreased). Chi-square tests or logistic regression analysis were used to compare differences in the predictors between these two groups. All analyses were two-tailed, and the probability level of $\mathrm{P}<0.05$ indicated statistical significance. IBM SPSS Statistics 22.0 was used to conduct the analyses.

\section{RESULTS}

\section{Characteristics of the sample}

$29(39 \%)$ of the participants were females. A more detailed description of the sample is presented in Table 3.

Table 3 about here

\section{Cognitive performance at the baseline and follow-up and change of cognitive performance}

There was a statistically significant decline in all seven studied CVLT items but no change in VOLT and AIM (Table 4).

Table 4 about here 


\section{Association between predictors and cross-sectional cognitive performance at the}

\section{baseline}

After B-H correction, women had higher verbal learning at baseline compared to men. Primary school marks of all subjects, and theoretical and practical subjects associated positively with five CVLT items and AIM, abstraction with memory. Vocational education was statistically significantly associated with four CVLT items and with AIM, abstraction with memory at baseline: those with the lowest vocational education had poorer cognitive performance compared to those with middle or high vocational education. Managerial employees had higher recall consistency in CVLT at baseline compared to official level employees or employees and others (students and unemployed) (Table 5).

Table 5 about here

\section{Predictors of change in cognitive performance in nine-year follow-up}

Gender was significantly associated with change in CVLT. Males had a larger decrease compared to females in span of apprehension $\left(\right.$ beta $\left.=0.28, p=0.004, p_{B-H}=0.013\right)$, immediate free recall $\left(\right.$ beta $\left.=0.35, p=0.003, p_{B-H}=0.016\right)$, and short delay free recall $($ beta $\left.=0.35, p=0.003, p_{B-H}=0.030\right)$. Uncorrected for multiple comparisons, poor school marks of practical subjects predicted more decline in immediate free recall (beta $=0.27, p=0.032$, $\left.p_{B-H}=0.11\right)$ and short delay $\left(\right.$ beta $\left.=0.28, p=0.023, p_{B-H}=0.12\right)$, though non-significantly after B-H correction. Likewise, increasing of memory strategy biases during episodic memory task measured by all intrusions was associated with having no children $($ beta $=-$ $\left.0.26, p=0.014, p_{B-H}=0.070\right)$ and increase in BMI $\left(\right.$ beta $\left.=0.26, p=0.018, p_{B-H}=0.18\right)$ (Table 6). 
Table 6 about here

Primary school marks of all school subjects $\left(\right.$ beta $\left.=0.33, p=0.002, p_{B-H}=0.020\right)$, theoretical $\left(\right.$ beta $\left.=0.32, p=0.002, p_{B-H}=0.020\right)$ and practical subjects $($ beta $=0.30, p=$ $\left.0.004, p_{B-H}=0.040\right)$, vocational education $\left(\right.$ beta $\left.=0.28, p=0.007, p_{B-H}=0.070\right)$ and occupational class $\left(\right.$ beta $\left.=0.31, p=0.003, p_{B-H}=0.030\right)$ were associated with performance in VOLT: among those with lowest primary school marks, lowest vocational education or lowest employment status, performance decreased; whereas among those with highest primary school marks, highest vocational education or highest employment status, performance increased. Having children predicted decreased performance in AIM abstraction with memory but non-significantly after B-H correction $\left(\right.$ beta $\left.=-0.21, p=0.012, p_{B-H}=0.12\right)$, whereas none of the predictors associated to change in AIM abstraction without memory (Table 7).

Table 7 about here

\section{Difference between 'preserved cognitive performance'vs. 'decreased cognitive}

\section{performance'groups}

In a post hoc analysis, we analysed how those with 'preserved cognitive performance' differed from those with 'decreased cognitive performance'. Good primary school marks were associated with preserved cognitive performance regarding all school subjects (OR, odds ratio 2.6; 95\% CI, 95\% confidence interval 1.4, 4.7), theoretical subjects $(2.1 ; 1.3,3.5)$, and practical subjects $(2.9 ; 1.2,6.7)$. Within those with preserved cognitive performance, $54 \%$ had high and $27 \%$ low education, whereas within those with 'decreased cognitive performance', $24 \%$ had high and 55\% low education $(p=0.017)$. Likewise, within those with 
'preserved cognitive performance', $43 \%$ were managerial employees and $27 \%$ employees or others, whereas within those with 'decreased cognitive performance', $18 \%$ were managerial employees and 53\% employees or others $(p=0.032)$. The other predictors did not differ between these two groups.

\section{DISCUSSION}

This study had several key findings regarding predictors of change of cognitive ability in the general population at early midlife. There was a statistically significant decline in all studied measures of verbal learning and memory. Performance among visual object learning and memory and executive functioning remained unchanged. Male gender predicted statistically significantly decrease in episodic memory in nine-year follow-up. Also poor school marks of practical subjects, having no children, and increase in BMI were associated with decrease in episodic memory, though non-significantly after B-H correction. Better primary school marks of theoretical, practical and all school subjects and higher occupational class were significantly associated with preserved performance in visual object learning. Also, uncorrected for multiple comparisons, higher vocational education predicted preserved performance in visual object learning test, though non-significantly after B-H correction. Likewise, having children predicted decreased performance in executive functioning but nonsignificantly after corrected for multiple comparisons. Marital status did not associate with change in cognitive ability.

There are heterogeneous findings related to predictors for cognitive decline in later life (Prince et al., 2012; Marioni, van den Hout, Valenzuela, Brayne, \& Matthewe, 2012). Gender differences in cognitive ability have been purported to reflect biological (Gur et al., 2000; Li et al., 2004; Cowell, Allen, Zalatimo, \& Denenberg, 1992; Silverman, Kastuk, Choi, \& Phillips, 1999) and social (Verma, Balhara, \& Gupta, 2011) factors that both contributes to daily functioning in the context of cognitive decline. Previous studies have linked female 
gender to greater deterioration in cognitive functioning, suggesting that incidence and prevalence of dementia in women is higher compared to men (Jorm \& Jolley, 1998; Launer et al., 1999). Somewhat surprisingly, and not supporting our hypothesis, male gender predicted more decline of cognitive ability during episodic memory task. However, consistent with the previous reports (Matthews et al., 2004; Muniz-Terrera et al., 2009), our findings indicate that adults demonstrate progressive cognitive decline possibly moderated by specific gender differences. The current study extends previous findings by showing that gender-associated decline occurs already in early midlife.

Further, poor primary school marks at age of 16 years predicted greater decline in episodic memory and was associated with performance in visual object learning. To our knowledge, there are no earlier studies on school performance as a predictor of longitudinal change of cognitive ability in early midlife in unselected general-population sample. The concept of cognitive reserve might be a potential explanation for association between adolescent cognitive performance and later change of cognitive ability. The ability of the mind to compensate in some way for brain changes has been proposed in dementia and ageing research as a moderator between brain change and cognitive outcome (Stern, 2012). In our study lower school marks at age 16-years predicted more decline of cognitive ability in middle-aged adults. It may be that individuals with better adolescent cognitive ability can somehow compensate for age-related changes, perhaps by employing alternative cognitive and/or neural strategies to solve cognitive problems in unorthodox ways (Murray et al., 2010).

Also, in concordance with previous studies, the current study found that higher vocational education and better occupational class were associated with less decline in cognitive performance. The protective effects of higher education and occupation-based social class on cognitive ability have been previously demonstrated in old age cohorts 
(Christensen, 2001; Matthews et al., 2012). It has been suggested however that more recent birth cohorts are better educated and perform better cognitively (Matthews et al., 2012). Coupled with developing a broad level of physical illnesses and dementia, and the high loss of participants to follow-up, the findings from previous studies have to be regarded with caution.

Parenthood seemed to have heterogeneous effects on cognitive change. This variable can be considered as a form of general well-being. In this way, our results are consistent with previous studies on association between cognitive changes and individual-difference factors, such as social conditions and general well-being (McCarty, Siegler, \& Logue, 1982; Rönnlund et al., 2005; Zelinski \& Burnight, 1997).

Finally, increase in BMI was associated with increasing of memory strategy biases among episodic memory. Obesity in middle age has been shown to increase the risk for latelife cognitive decline and dementia (Kivipelto et al., 2005). Much is already known about association between baseline BMI and cognitive changes, though mostly in adults aged 65 years and older (Elias, Elias, Sullivan, Wolf, \& D’Agostino, 2005; Kivipelto et al., 2005; Sturman et al., 2008; Tolppanen et al., 2014; Wolf et al., 2007). We further investigated the impact of BMI on cognitive status and extend previous findings by studying BMI change as a predictor for cognitive decline in middle-aged adults.

The current study uses a population-based long-term follow-up design that may decrease the potential for sample selection bias. The study design may provide values for the evaluation of factors of change in cognitive functioning in early midlife that could potentially be used in future interventional studies. Compared to previous studies with usually short follow-ups, a long (nine-year) follow-up interval from age 34 to age 43 years was applied in our research, which may contribute towards understanding the temporal correlations between individual-difference factors and change of cognitive ability in early midlife. Furthermore, 
the current study is one of the first concerning the association between longitudinal change in cognitive performance and primary school achievements, sociodemographic predictors and BMI in the general population. We maximised the re-test reliability by using identical measures of cognitive performance - the CVLT, VOLT and AIM - at both time points.

This study has also various limitations. The number of subjects was relatively small. However, the birth cohort sample drawn from the same aged participants is likely to be free of the biases that can be associated with clinical and convenience samples, and helps to minimize variance caused by age variation. Also, any observed associations may be confounded by unmeasured factors. For example, all confounding factors occurring during the long follow-up interval are impossible to control for even though the most important confounders were taken into account. It is possible that our findings may reflect a true causal association but they may also be explained by uncontrolled third factor. Due to relatively small sample size the analyses were not mutually adjusted and interaction effects were not analysed. However, all the analyses of this study were conducted by using inverse probability weighting to correct for the distribution of gender and education in our sample.

Additionally, the study sample was originally planned as a control group for a casecontrol study on psychosis. Given that psychotic disorders are more prevalent among men, they wind up being better represented in the sample than women. In studies with similarly unequal gender distribution (e.g. Agrigoroaei and Lachman, 2011; Colsher and Wallace, 1991; Giambra et al., 1995; Hahn and Lachman, 2015), the association between gender differences and course of cognitive development have been similarly observed.

Our sample was higher educated than the whole cohort due to recruiting procedure. The subjects were selected randomly from the NFBC 1966 members without a psychotic episode, living in the region of Oulu where vocational education is higher in comparison to that in other northernmost Finnish provinces. In addition to above-mentioned, we were not 
able to evaluate a detailed cognitive profile of the participants due to concise cognitive battery; we had a limited number of predictors and we did not have any questionnaires on psychiatric symptomatology. We do not have information on physical activity. The measures of height and weight used for forming BMI were determined by self-reports, which may not be completely accurate.

There is evidence that cognitive decline increases with age and that the change of cognitive ability can be predicted by a number of risk factors. We extended the previous findings showing that cognitive decline seems to occur even in early midlife in relation to specific gender differences, adolescent cognitive ability, parenthood, education and occupational class, and change in BMI. Additional investigations of risk factors of cognitive change over time in large population-based longitudinal studies are needed.

\section{ACKNOWLEDGMENTS}

This work was supported in part by grants from the Academy of Finland (\#132071, \#268336, \#278286) as well as the Sigrid Jusélius Foundation, Northern Finland Health Care Support Foundation, Jalmari and Rauha Ahokas Foundation: Brain and Behavior Research Foundation, and the UK Medical Research Council. The funders had no role in the design or conduct of the study.

\section{REFERENCES}

Agrigoroaei, S. \& Lachman, M.E., (2011).Cognitive functioning in midlife and old age: combined effects of psychosocial and behavioral factors. The Journals of Gerontology Series B: Psychological Sciences and Social Sciences, 66 (Suppl 1:i), 130-140. doi:10.1093.

Anderson, P., Anderson, V. A., Northam, E., Jacobs, R., \& Catroppa, C. (2001). Development of executive functions through late childhood and adolescence in an Australian sample. Developmental Neuropsychology, 20, 385-406.

Bielak, A.A., Anstey, K.J., Christensen, H., \& Windsor, T.D., (2012). Activity engagement is related to level, but not change in cognitive abilityacross adulthood. Psychology and Aging, 27(1), 219-228. doi: 10.1037/a0024667. 
Carmelli, D., Swan, G.E., LaRue, A., \& Eslinger, P.J., (1997). Correlates of change in cognitive function in survivors from the Western Collaborative Group Study. Neuroepidemiology, 16(6), 285-295.

Christensen, H. (2001). What cognitive changes can be expected with normal aging? Australian and New Zealand Journal of Psychiatry, 35, 768 - 775. doi: 10.1046/j.1440-1614.2001.00966.x

Clark, C.R., Paul, R.H., Williams, L.M., Arna, M., Fallahpour, K., Hadmen, C., \& Gordon, E. (2006). Standardized assessment of cognitive functioning during development and aging using an automated touchscreen battery. Archives of Clinical Neuropsychology, 21(5), 449 - 467. doi:10.1016/j.acn.2006.06.005

Colsher, P. L., \& Wallace, R., B. (1991). Longitudinal application of cognitive function measures in a defined population of community-dwelling elders. Annual of Epidemiology, 1, 215 - 230. Retrieved from http://www.ncbi.nlm.nih.gov/pubmed/1669503

Cournot, M., Marquié, J. C., Ansiau, D., Martinaud, C., Fonds, H., Ferrières, J., \& Ruidavets, J. B., (2006). Relation between body mass index and cognitive function in healthy middle-aged men and women. Neurology, 67, 1208-1214. doi:

10.1212/01.wnl.0000238082.13860.50

Cowell, P. E., Allen, L. S., Zalatimo, N. S., \& Denenberg, V. H. (1992). A developmental study of sex and age interactions in the human corpus callosum. Developmental Brain Research, 66(2), 187-192. Retrieved from http://www.ncbi.nlm.nih.gov/pubmed/1606684

Delis, D.C., Kramer, J. H., Kaplan, E., \& Ober, B.A. (1987). California Verbal Learning Test. Manual for CVLT. Psychological Corporation. New York.

Desmond, D.W., (2004). The neuropsychology of vascular cognitive impairment: is there a specific cognitive deficit? The Journal of Neurological Sciences, 226, 3-7.

Elias, M.F., Elias, P.K., Sullivan, L.M., Wolf, P.A., D'Agostino, R.B., (2005). Obesity, diabetes and cognitive deficit: the Framingham Heart Study. Neurobiology of Aging, 26 (suppl 1), $11-16$.

Finkel, D., Pedersen, N., Plomin, R., \& McClearn, G. E., (1998). Longitudinal and crosssectional data on cognitive abilities in adulthood: The Swedish adoption/twin study of aging. Developmental Psychology, 34(6), 1400 - 1413. Retrieved from http://www.ncbi.nlm.nih.gov/pubmed/?term=Finkel+1998+Longitudinal+and+cross- 
sectional+data+on+cognitive+abilities+in+adulthood\%3A+The+Swedish+adoption\% 2Ftwin+study+of+aging.

Furuäng, L., Wollmer, P., Siennicki-Lantz, A., \& Elmståhl, S., (2013). Cardiac ventricular dimensions predict cognitive decline and cerebral blood flow abnormalities in aging men. BMC Geriatrics, 13, 45. doi: 10.1186/1471-2318-13-45.

Giambra, L. M., Arenberg, D., Zonderman, A. B., Kawas, C., \& Costa, P. T. (1995). Adult life span changes in immediate visual memory and verbal intelligence. Psychology and Aging, 10, 123 - 139. Retrieved from http://www.ncbi.nlm.nih.gov/pubmed/7779310

Glahn, R. C., Gur, J. D., Raglanf, D. M., Censits, R. E., \& Gur, R. E. (1997). Reliability, performance characteristics, construct validity, and an initial clinical application of a visual object learning test (VOLT). Neuropsychology, 11(4), 602-612. Retrieved from

http://www.ncbi.nlm.nih.gov/pubmed/?term=Glahn+1997+Reliability\%2C+performa nce+characteristics $\% 2 \mathrm{C}+$ construct+validity $\% 2 \mathrm{C}+$ and $+\mathrm{an}+\mathrm{initial}+\mathrm{clinical}+$ application +of+a+visual+object+learning+test+\%28VOLT\%29.

Glahn, D. C., Cannon, T. D., Gur, R. E., Ragland, J. D., \& Gur, R. C. (2000). Abstraction and Memory in Schizophrenia. Biological Psychiatry, 47(1), 34-42. Retrieved from http://www.ncbi.nlm.nih.gov/pubmed/?term=Glahn+2000+Abstraction+and+Memory + in + Schizophrenia.

Glynn, R.J., Beckett, L.A., Hebert, L.E., Morris, M.C., Scherr, P.A., \& Evans, D.A., (1999). Current and remote blood pressure and cognitive decline. JAMA, 281(5), 438-445.

Gur, R. C., Alsop, D., Glahn, D., Petty, R., Swanson, C. L., Maldjian, J. A., Turetsky, B. I., Detre, J. A., Gee, J., Gur, R. E. (2000). An fMRI study of sex differences in regional activation to a verbal and a spatial task. Brain and Language, 74(2), 157-170.

Retrieved from http://www.ncbi.nlm.nih.gov/pubmed/10950912

Haapea, M., Miettunen, J., Veijola, J., Lauronen, E., Tanskanen, P., \& Isohanni, M. (2007). Non-participation may bias the results of a psychiatric survey: an analysis from the survey including magnetic resonance imaging within the Northern Finland 1966 Birth Cohort. Social psychiatry and psychiatric epidemiology, 42(5), 403 - 409. Retrieved from http://www.ncbi.nlm.nih.gov/pubmed/?term=Haapea+2007+Nonparticipation+may+bias+the+results+of $+a+$ psychiatric + survey $\% 3 \mathrm{~A}+\mathrm{an}+$ analysis + fro $\underline{m+\text { the+survey+including+magnetic+resonance+imaging+within+the+Northern+Finla }}$ $\underline{\text { nd }+1966+\text { Birth}+ \text { Cohort. }}$ 
Hahn, E. A. \& Lachman, M. E. (2015). Everyday experiences of memory problems and control: the adaptive role of selective optimization with compensation in the context of memory decline. Aging, Neuropsychology, and Cognition, 22(1), 25 - 41. doi.org/10.1080/13825585.2014.888391

Halpern, D. F. (1992). Sex differences in cognitive abilities (2nd ed.). Hillsdale, NJ: L. Erlbaum Associates. Retrieved from http://www.google.fi/books?hl=fi\&lr=\&id=ocl5AgAAQBAJ\&oi=fnd\&pg=PP1\&dq= Halpern,+D.+F.+(1992).+Sex+differences+in+cognitive+abilities+(2nd+ed.).\&ots=W BcSxewmfi\&sig=GvaErWCpOiBaejNui7wSArOu73w\&redir_esc=y\#v=onepage\&q= Halpern\%2C\%20D.\%20F.\%20(1992).\%20Sex\%20differences\%20in\%20cognitive\%2 0abilities\%20(2nd\%20ed.).\&f=false

Hayslip, B., \& Kennelly, K. J. (1985). Cognitive and noncognitive factors affecting learning among older adults. In D. B. Lumsden (Ed.), The older adult as learner: Aspects of educational gerontology (pp. 73 -98). Washington, DC: Hemisphere.

Herlitz, A., Airaksinen, E., \& Nordstrom, E. (1999). Sex differences in episodic memory: the impact of verbal and visuospatial ability. Neuropsychology, 13(4), 590-597. Retrieved from

http://www.ncbi.nlm.nih.gov/pubmed/?term=Herlitz+1999+Sex+differences+in+epis odic+memory\%3A+the+impact+of+verbal+and+visuospatial+ability.

Hultsch, D. F., \& Dixon, R. A. (1984). Memory for text matrials in adulthood. In P. B. Baltes \& O. C. Brim, Jr. (Eds.), Life-span development and behavior, 6, (pp. 77 - 108). An Diego, CA: Academic Press.

Hyde, J. S., \& McKinley, N. M. (1997). Gender differences in cognition: results from metaanalyses. In P. J. Caplan, M. Crawford, J. S. Hyde, \& J. T. E. Richardson (Eds.), Gender differences in human cognition (pp.vi, 182 p.). New York: Oxford University Press.

Johansson, B., Zarit, S. H., \& Berg, S. (1992). Changes in cognitive functioning of the oldest old. Journals of Gerontology, Series B: Psychological Sciences and Social Sciences, 47(2), 75 - 80. Retrieved from http://www.ncbi.nlm.nih.gov/pubmed/?term=Johansson+1992+Changes+in+cognitive + functioning+of + the+oldest+old.

Johansson, B., Hofer, S.M., Allaire, J.C., Maldonado-Molina, M.M., Piccinin, A.M., Berg, S., Pedersen, N.L., \& McClearn, G.E., (2004). Change in cognitive capabilities in the 
oldest old: the effects of proximity to death in genetically related individuals over a 6year period. Psychology and Aging, 19(1), 145-156.

Johnson, W., Price, J.F., Rafnsson, S.B., Deary, I.J., \& Fowkes, F.G., (2010). Ankle--brachial index predicts level of, but not change in, cognitive function:the Edinburgh Artery Study at the 15-year follow-up. Vasc Med, 15(2), 91-97. doi: $10.1177 / 1358863 X 09356321$.

Jorm, A. F. (1986). Cognitive deficit in the depressed elderly: a review of some basic unresolved issues. Australian and New Zealand Journal of Psychiatry, 20(1), 11-22. Retrieved from http://www.ncbi.nlm.nih.gov/pubmed/?term=Jorm+1986+Cognitive+deficit+in+the+ depressed+elderly\%3A+a+review+of+some+basic+unresolved+issues.

Jorm, A.F., Jolley, D., (1998). The incident of dementia: a meta-analysis. Neurology, 51(3), 728-733.

Kivipelto, M., Helkala, E. L., Hanninen, T., Laakso, M. P., Hallikainen, M., Alhainen, K., Soininen, H., Tuomilehto, J., \& Nissinen, A. (2001). Midlife vascular risk factors and late-life cognitive impairment: a population-based study. Neurology, 56(12), 16831689. Retrieved from http://www.ncbi.nlm.nih.gov/pubmed/?term=Kivipelto+2001+Midlife+vascular+risk + factors+and+late-life+cognitive+impairment $\% 3 \mathrm{~A}+\mathrm{a}+$ population-based+study.

Kivepelto, M., Ngandu, T., Fratiglioni, L., Viitanen, M., Kåreholt, I., Winblad, B., Helkala, E.L., Tuomilehto, J., Soininen, H., Nissinen, A., (2005) Obesity and vascular risk factors at midlife and the risk of dementia and Alzheimer disease. Archives of Neurology, 62, 1556-1559.

Kobayashi, H., Isohanni, M., Jääskeläinen E., Miettunen, J., Veijola, J., Haapea, M., Järvinen, M.-R., Jones, P. B., \& Murray, G. (2014). Linking the developmental and degenerative theories of schizophrenia: association between infant development and adult cognitive decline. Schizophrenia Bulletin, 40(6), 1319-1327. doi:10.1093/schbul/sbu010.

Kopelman, P.G., (2000). Obesity as a medical problem. Nature, 404, 635 - 643.

Korkman, M., Kemp, S. L., \& Kirk, U. (2001). Effects of age on neurocognitive measures of children ages 5 to 12: A cross-sectional study on 800 children from the United States. Developmental Neuropsychology, 20(1), 331-354. 
Launer, L.J., Andersen, K., Dewey, M.E., Letenneur, L., Ott, A., Amaducci, L.A., Brayne, C., Copeland, J.R., Dartigues, J.F., Kragh-Sorensen, P., et al., (1999). Rates and risk factors for dementia and Alzheimer's disease: results from EURODEM pooled analyses. EURODEM Incidence Research Group and Work Groups. European Studies of Dementia. Neurology, 52(1), 78-84.

Maller, J. J., Anstey, K. J., Réglade-Meslin, C., Christensen, H., Wen, W., \& Sachdev, P. (2007). Hippocampus and amygdala volumes in a random community-based sample of 60-64 year olds and their relationship to cognition. Psychiatry Research: Neuroimaging, 156(3), 185-197. Retrieved from http://www.ncbi.nlm.nih.gov/pubmed/?term=Maller+2007+Hippocampus+and+amyg dala+volumes+in+a+random+communitybased+sample+of+60\%E2\% $80 \% 9364+$ year+olds+and+their+relationship+to+cogniti on.

Matthews, F., Marioni, R., \& Brayne, C.; Medical Research Council Cognitive Functionand Ageing Study, (2012). Examining the influence of gender, education, social class and birth cohort on MMSE tracking over time: a population-based prospective cohort study. BMC Geriatrics, 12, 45. doi: 10.1186/1471-2318-12-45.

Mayeux, R., Small, S. A., Tang, M.-X., Tycko, B., \& Stern, Y. (2001). Memory performance in heathy elderly without Alzheimer's disease: effects of time and apolipoprotein-E. Neurobiology of Aging, 22(4), 683 - 689. Retrieved from http://www.ncbi.nlm.nih.gov/pubmed/?term=Mayeux+2001++Memory+performance +in+heathy+elderly+without+Alzheimer\%E2\%80\%99s+disease\%3A+effects+of+tim e+and+apolipoprotein-E.

McCarty, S. M., Siegler, I. C., \& Logue, P. E. (1982). Cross-sectional and longitudinal patterns of three Wechsler Memory subtests. Journal of Gerontology, 37(2), 169 175. Retrieved from http://www.ncbi.nlm.nih.gov/pubmed/?term=McCarty+1982++Cross$\underline{\text { sectional+and+longitudinal+patterns+of+three+Wechsler+Memory+subtests }}$

MacDonald, S.W., Dixon, R.A., Cohen, A.L., \& Hazlitt, J.E., (2004). Biological age and 12year cognitive change in older adults: findings from the Victoria Longitudinal Study. Gerontology, 50(2), 64-81.

McDonald-Miszczak, L., Hertzog, C., \& Hultsch, D. F. (1995). Stability and accuracy of metamemory in adulthood and aging: a longitudinal analysis. Psychology and Aging, 10(4), 553 - 564. Retrieved from http://www.ncbi.nlm.nih.gov/pubmed/8749582 
Marioni, R.E., van den Hount, A., Valenzuela, M.J., Braynem C., and Matthews, F.E., (2012). Active cognitive lifestyle associates with cognitive recovery and a reduced risk of cognitive decline. Journal of Alzheimer's Disease, 28(1), 223-230.

Miyake, A., Friedman, N. P., Emerson, M. J., Witzki, A. H., \& Howerter, A. (2000). The unity and diversity of executive functions and their contributions to complex "frontal lobe" tasks: a latent variable analysis. Cognitive Psychology, 41, 49 - 100. doi: 10.1006/cogp.1999.0734

Muniz-Terrera, G., Matthews, F., Dening, T., Huppert, F.A., Brayne, C.; CC75C Group, (2009). Education and trajectories of cognitive decline over 9 years in very old people: methods and risk analysis. Age and Ageing, 38(3), 277-282. doi: 10.1093/ageing/afp004.

Munro, C. A., Winicki, J. M., Schretlen, D. J., Gower, E. W., Turano, K. A., Munoz, B., Keay, L., Bandeen-Roche, K., \& West, S. K. (2012). Sex differences in cognition in healthy elderly individuals. Neuropsychology, development, and cognition. Section B, Aging and cognition, 19(6), 759 - 768. doi: 10.1080/13825585.2012.690366

Murray, G.K., Corlett, P.R., Fletcher, \& P.C., (2010). The neural underpinnings of associative learning in health and psychosis: how can performance be preserved when brain responses are abnormal? Schizophrenia Bulletin, 36 (3), 465-471.

Nguyen, H.T., Black, S.A., Ray, L.A., Espino, D.V., \& Markides, K.S., (2002). Predictors of decline in MMSE scores among older Mexican Americans. The Journals of Gerontology Series A: Biological Sciences and Medical, 57(3), M181-5.

Orrell, M. \& Sahakian, B. (1995). Education and dementia. British Medical Journal, 310, 951-952. Retrieved from http://www.ncbi.nlm.nih.gov/pmc/articles/PMC2549351/pdf/bmj00588-0005.pdf

Osler, M., Avlund, K., \& Mortensen, E.L., (2013). Socio-economic position early in life, cognitive development and cognitive change from young adulthood to middle age. The European Journal of Public Health, 23(6), 974-980. doi: 10.1093/eurpub/cks140.

Payne, B.R., Gross, A.L., Parisi, J.M., Sisco, S.M., Stine-Morrow, E.A., Marsiske, M., \& Rebok, G.W., (2014). Modelling longitudinal changes in older adults' memory for spoken discourse: findings from the ACTIVE cohort. Memory, 22(8), 990-1001. doi: 10.1080/09658211.2013.861916. 
Piccinin, A.M., Muniz, G., Sparks, C., Bontempo, D.E., (2011). An evaluation of analytical approaches for understanding change in cognition in the context of aging and health. The journals of gerontology. Series B, Psychological sciences and social sciences, 66(Suppl 1): 36-49.

Prince, M., Acosta, D., Ferri, C.P., Guerra, M., Huang, Y., Rodriguez, J.J., Salas, A., Sosa, A.L., Williams, J.D., Dewey, M.E., et al., (2012). Dementia incidence and mortality in middle-income countries, and associations with indicators of cognitive reserve: a 10/66 Dementia Research Group population-based cohort study. Lancet, 380(9836), $50-58$.

Rannikko, I., Haapea, M., Miettunen, J., Veijola, J., Murray, G.K., Barnett, J.H., Husa, A.P., Jones, P.B., Isohanni, M., Jääskeläinen, E., (2015). Changes in verbal learning and memory in schizophrenia and non-psychotic controls in midlife: A nine-year followup in the Northern Finland Birth Cohort 1966 study. Psychiatry Research, 228(3), 671-679. doi: 10.1016/j.psychres.2015.04.048.

Rantakallio, P., (1988). The longitudinal study of the northern Finland birth cohort of 1966. Pediatric and Perinatal Epidemiology, 2(1), 59 - 88.

Ramscar, M., Hendrix, P., Shaoul, C., Milin, P., \& Baayen, H. (2014). The myth of cognitive decline: non-linear dynamics of lifelong learning. TopiCS, 6(1), 5-42. doi: 10.1111/tops.12078

Richards, M., Shipley, B., Fuhrer, R., \& Wadsworth, M.E., (2004). Cognitive ability in childhood and cognitive decline in mid-life: longitudinal birth cohort study. British Medical Journal, 328(7439), 552. doi: 10.1136/bmj.37972.513819.EE

Ridler, K., Veijola, J. M., Tanskanen, P., et al. (2006). Fronto-cerebellar systems are associated with infant motor and adult executive functions in healthy adults but not in schizophrenia. Proceeding of the National Academy of Sciences, 103(42), 15651 15656.

Rönnlund, M., Nyberg, L., Bäckman, L., \& Nilsson, L.G. (2005). Stability, growth, and decline in adult life span development of declarative memory: cross-sectional and longitudinal data from a population-based study. Psychology and Aging, 20(1), 3-18. Retrieved from http://www.ncbi.nlm.nih.gov/pubmed/?term=R\%C3\%B6nnlund+2005+Stability\%2C +growth $\% 2 \mathrm{C}+$ and +decline+in+adult+life+span+development+of+declarative+memor $\mathrm{y} \% 3 \mathrm{~A}+$ cross-sectional+and+longitudinal+data+from+a+population-based+study. 
Salthouse, T. A. (2009). When does age-related cognitive decline begin? Neurobiology of Aging, 30(4), 507 - 514. doi: 10.1016/j.neurobiolaging.2008.09.023

Salthouse, T. (2000). Aging and measures of processing speed. Biological Psychology, 54, $35-54$.

Salthouse, T. (2001). Structural models of the relations between age and measures of cognitive functioning. Intelligence, 29, 93-115.

Schaie, K. W. (1994). The course of adult intellectual development. American Psychologist, 49(4), $304-313$. Retrieved from http://search.proquest.com.pc124152.oulu.fi:8080/docview/614322501/fulltext/8752A 08E419F4ED9PQ/27?accountid=13031http://www.ncbi.nlm.nih.gov/pubmed/?term= $\underline{\text { Schaie+1994+The+course+of+adult+intellectual+development. }}$

Silverman, I., Kastuk, D., Choi, J., \& Phillips, K. (1999). Testosterone levels and spatial ability in men. Psychoneuroendocrinology, 24(8), 813-822. Retrieved from http://www.ncbi.nlm.nih.gov/pubmed/?term=Silverman+1999+Testosterone+levels+a nd+spatial+ability+in+men.

Sing-Manoux, A., Kivimaki, M., Glymour, M. M., Elbaz, A., Berr, C., Ebmeier, K. P., \& Dugravot, A. (2012). Timing of onset of cognitive decline: results from Whitehall II prospective cohort study. British Medical Journal, 344, d7622. doi:

10.1136/Bmj.D7622

Stern, J., (2012). Cognitive reserve in ageing and Alzheimer's disease. The Lancet Neurology, $11(11), 1006-1012$.

Sturman, M.T., de Leon, C.F., Bienias, J.L., Morris, M.C., Wilson, R.S., \& Evans, D.A., (2008). Body mass index and cognitive decline in a biracial community population. Neurology, 70(5), 360-367.

Tolppanen, A. M., Ngandu, T., Kåreholt, I., Laatikainen, T., Rusanen, M., Soininen, H., \& Kivipelto, M. (2014). Midlife and late-life body mass index and late-life dementia: results from a prospective population-based cohort. Journal of Alzheimer's disease, 38(1), 201-9. doi: 10.3233/JAD-130698

Tomaszewski Farias, S., Mungas, D., Hinton, L., \& Haan, M. (2011). Demographic, neuropsychological and functional predictors of rate of longitudinal cognitive decline in Hispanic older adults. The American Journal of Geriatric Psychiatry, 19(5), 440450. doi: 10.1097/JGP.0b013e3181e9b9a5

van Hooren, S. A., Valentijn, A. M., Bosma, H., Ponds, R. W., van Boxtel, M. P., \& Jolles, J. (2007). Cognitive functioning in healthy older adults aged 64-81: A cohort study into 
the effects of age, sex, and education. Aging, Neuropsychology, and Cognition, 14(1), 40-54. Retrieved from

http://www.ncbi.nlm.nih.gov/pubmed/?term=van+Hooren+2007++Cognitive+functio ning+in+healthy+older+adults+aged+64\%E2\%80\%9381\%3A+A+cohort+study+into +the+effects+of+age $\% 2 \mathrm{C}+\operatorname{sex} \% 2 \mathrm{C}+$ and+education.

Veijola, J., Guo, J. Y., Moilanen, J. S., Jääskeläinen, E., Miettunen, J., Kyllönen, M., Haapea, M., Huhtaniska, S., Alaräisänen, A., Mäki, P., Kiviniemi, V., Nikkinen, J., Starck, T., Remes, J. J., Tanskanen, T., Tervonen, O.,Wink, A.-M., Kehagia, A., Suckling, J., Kobayashi, H., Barnett, J. H., Barnes, A., Koponen, H. J., Jones, P. B., Isohanni, M., \& Murray, G. K. (2014). Longitudinal Changes in Total Brain Volume in Schizophrenia: Relation to Symptom Severity, Cognition and Antipsychotic Medication. PLoS One, 9(7):e101689. doi: 10.1371/journal.pone.0101689

Verma, R., Balhara, J. P. S., \& Gupta, C. S. (2011). Gender differences in stress response: Role of developmental and biological determinants. Industrial Psychiatry Journal, 20(1), 4-10. doi: 10.4103/0972-6748.98407

West, R. L., Crook, T. H., \& Barron, K. L. (1992). Everyday memory performance across the life span: effects of age and noncognitive individual differences. Psychology and Aging, 7(1), 72-82. Retrieved from http://www.ncbi.nlm.nih.gov/pubmed/?term=West+1992+Everyday+memory+perfor $\underline{\text { mance+across }+ \text { the }+ \text { life }+ \text { span } \% 3 \mathrm{~A}+\text { effects+of }+ \text { age }+ \text { and+noncognitive+individual+dif }}$ ferences.

Wolf, P.A., Beiser, A., Elias, M.F., Au, R., Vasan, R.S., Seshadri, S., (2007). Relation of obesity to cognitive function: importance of central obesity and synergistic influence of concomitant hypertension. The Framingham Heart Study. Current Alzheimer Research, 4, $111-116$.

Zelinski, E. M., \& Burnight, K.P. (1997). Sixteen-year longitudinal and time lag changes in memory and cognition in older adults. Psychology and Aging, 12(3), 503 - 513. Retrieved from http://www.ncbi.nlm.nih.gov/pubmed/?term=Zelinski+1997+Sixteenyear+longitudinal+and+time+lag+changes+in+memory+and+cognition+in+older+adu lts. 


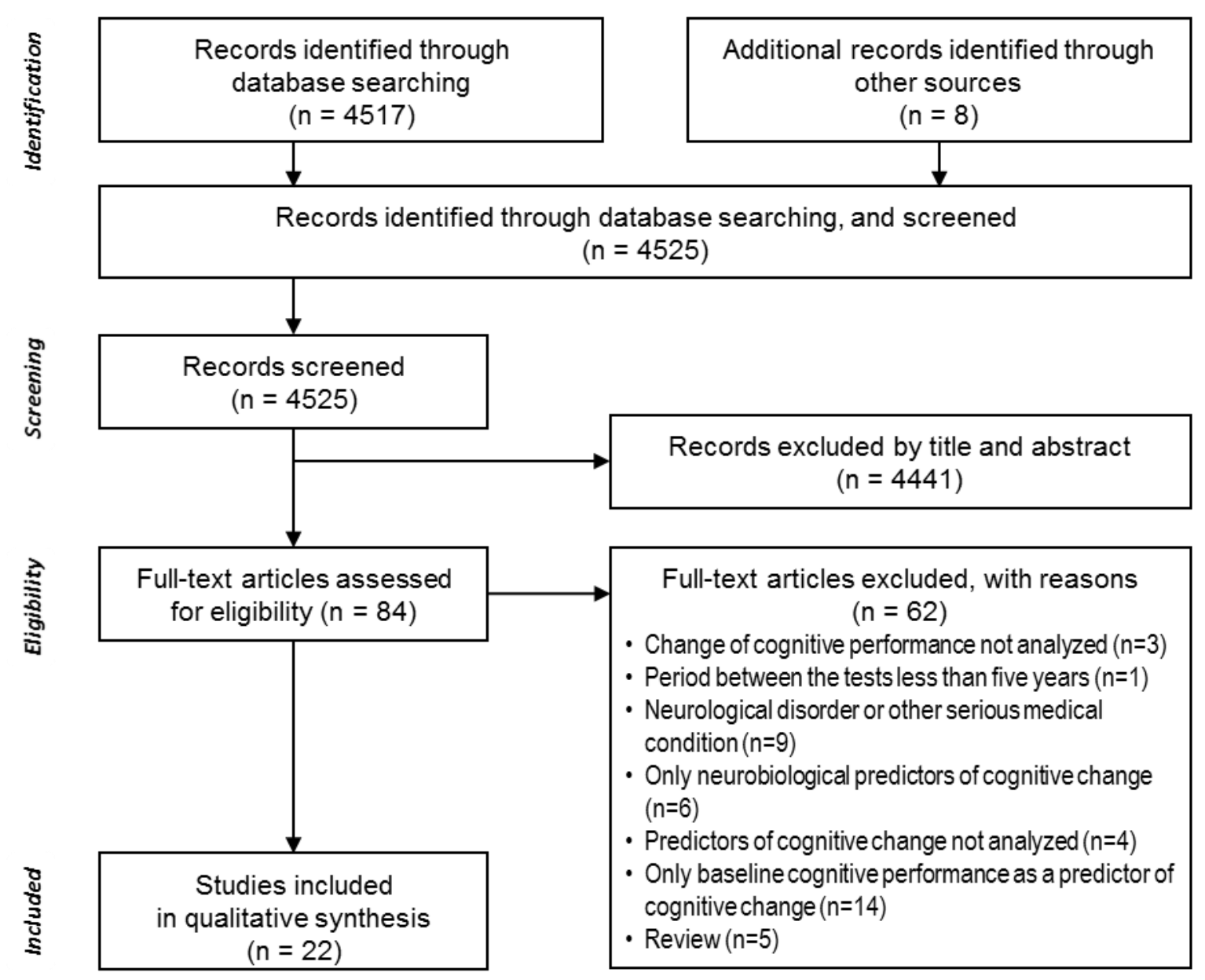

Methods of the systematic literature review:

The literature search was completed in in August 2015 using electronic database PubMed and manual searches.

The search strategy included keywords limited to title and abstract search:

(cognit ${ }^{*}$ Title/Abstract] AND change ${ }^{*}[$ Title/Abstract]AND predict*[Title/Abstract])

(NOT traumatic[Title/Abstract] NOT injury[Title/Abstract] NOT surgery[Titte/Abstract)] limited to human; English.

The articles included in the current systematic reviewwere required to meet the following criteria:

- sociodemographic and/or clinical predictors of longitudinal change in adult cognitive performance were analyzed

(e.g. studies analyzing only neurobiological predictors were excluded);

- the sample was not delineated to subjects with certain illness or disorder (i.e. general population samples or samples that included mostly individuals without any diagnosed neuropsychiatric disorders / dementia / mild cognitive impairment);

- standardized neuropsychological tests were used;

- the sample size was 20 or more;

- cognitive performance was measured at least two times with same tests;

- period between the tests was at least five years.

All of the abstracts were analyzed by the first author $(\mathbb{R})$. Problematic abstracts were evaluated in consensus.

In the second phase, the full-text articles were first read in full by the first author $(\mathbb{R})$ and all problematic articles were discussed in a meeting with the other authors.

Figure 1. Flowchart diagram of the literature search and selection of studies on predictors of change in cognitive performance in general population. 
Table 1. Studies and results concerning predictors of longitudinal change in cognitive performance in general population. Only studies with at least five years follow-up are included.

\begin{tabular}{|c|c|c|c|c|c|c|c|}
\hline $\begin{array}{l}\text { Authors } \\
\text { (Year) }\end{array}$ & Study design and sample & Follow-up & $\begin{array}{l}\text { Neuropsychological } \\
\text { assessments/domains }\end{array}$ & $\begin{array}{l}\text { Statistically } \\
\text { significant } \\
\text { results of } \\
\text { change in } \\
\text { cognition }\end{array}$ & Analyzed predictors & $\begin{array}{l}\text { Statistically } \\
\text { significant results } \\
\text { of predictors of } \\
\text { change in cognition }\end{array}$ & Comments \\
\hline $\begin{array}{l}\text { Agrigoroa } \\
\text { ei \& } \\
\text { Lachman } \\
(2011)\end{array}$ & $\begin{array}{l}\text { - } N=151 \text { ( } 43.7 \% \text { females) } \\
\text { persons from the Midlife } \\
\text { in the United States study } \\
\text { (MIDUS), who also } \\
\text { participated in a satellite } \\
\text { Boston Longitudinal Study } \\
\text { (BOLOS), Boston, U.S. } \\
\text { - average age at follow-up } \\
60 \text { years } \\
\text { - began between } 1995 \text { and } \\
\text { 1996; follow-up between } \\
2004 \text { and } 2005\end{array}$ & 10 years & $\begin{array}{l}\text { - Brief Test of Adult } \\
\text { Cognition by Telephone } \\
\text { (immediate and delayed } \\
\text { free recall of } 15 \text { words; } \\
\text { backward digit span; the } \\
\text { number of words produced } \\
\text { from the category of } \\
\text { animals in } 60 \mathrm{~s} \text {; } \\
\text { completing a pattern in a } \\
\text { series of } 5 \text { numbers; the } \\
\text { number of digits produced } \\
\text { by counting backward } \\
\text { from } 100 \text { in } 30 \text { s; the } \\
\text { Stroop and Go Swich } \\
\text { Task). } \\
\text { - Short-term memory; } \\
\text { speed of processing; } \\
\text { reasoning; vocabulary. }\end{array}$ & $\begin{array}{l}\text { - Decline in } \\
\text { short-term } \\
\text { memory, speed } \\
\text { of processing } \\
\text { and reasoning. }\end{array}$ & $\begin{array}{l}\text { - Baseline basic } \\
\text { demographic variables } \\
\text { (age/gender/education) } \\
\text { - Health status (e.g. } \\
\text { diabetes) } \\
\text { - Physical exercise } \\
\text { - Quality of social } \\
\text { support } \\
\text { - Control beliefs }\end{array}$ & $\begin{array}{l}\text { - A composite } \\
\text { index of the } \\
\text { number of adaptive } \\
\text { psychosocial and } \\
\text { behavioral factors } \\
\text { was positively } \\
\text { related to change in } \\
\text { reasoning abilities. } \\
\text { - Higher educated } \\
\text { participants } \\
\text { experienced } \\
\text { smaller memory } \\
\text { decline. }\end{array}$ & $\begin{array}{l}\text { Strengths: } \\
\text { - Longitudinal } \\
\text { interdisciplinary } \\
\text { study with long } \\
\text { follow-up period. } \\
\text { - Large cognitive } \\
\text { battery } \\
\text { Limitations: } \\
\text { - The } \\
\text { generalizability of } \\
\text { the findings is } \\
\text { limited to some } \\
\text { extent by the } \\
\text { positive selection of } \\
\text { the longitudinal } \\
\text { participants in } \\
\text { MIDUS and } \\
\text { BOLOS. }\end{array}$ \\
\hline
\end{tabular}


Bielak et $\quad N=7.125$ (approximately

al. (2012) $50 \%$ of each age cohort

was females) drawn from

the PATH Through Life

Project, Australia

- average age at follow-up 50 years

- baseline in 1999 - 2001;

follow-ups in 4 and 8

years

\section{Carmelli \\ et al.}

- $\mathrm{N}=566$ men, who are a

subsample of the

cardiovascular

epidemiologic study (the

Western Collaborative

Group Study), San

Francisco Bay and Los

Angeles areas, U.S.

- age at baseline 68 years

and older

- baseline between 1986

1988; follow-up between

1992 - 1994
8 years

$$
\bullet \text { Sym }
$$

Test

- California Verbal

Learning Test

- Digit Span Backward

from the Wechsler

Memory Scale

- Spot-the-Word Test
- The 60s

cohort: declines

in symbol digit,

and immediate

and delayed

recall with each

additional year

of being in the

study;

improvement on

the spot-the-

word task.

- The 20s and

40s cohorts:

improvement in

immediate and

delayed recall,

digit backward,

and spot-the-

word.

$\begin{array}{ll}6 \text { years } & \bullet \text { Digit Symbol } \\ & \text { Substitution test } \\ & \bullet \text { Benton Visual Retention } \\ & \text { Test }\end{array}$

- $20 \%$ of

subjects

Test

compared with

- Controlled Oral Word

Association Test

$17 \%$ who

improved in

cognitive

performance

from baseline to

follow-up.
- Activity level

- Between-person activity and withinperson variation in activity level were

both not

significantly

associated with

change in cognitive

test performance.
Strengths:

- According to the

authors, this is the

first investigation

of the association

between activity

and cognitive

change.
Baseline basic

demographic

variables(age/gender/e

ducation)

- Physical health

- Medical history

- Cardiovascular

history
- Poor self-

perceived health

ratings, depression

scale scores, and

self-reports of

physical activity

predicted decline in

cognitive

performance.
Strengths:

- Relatively large

sample

Limitations :

- The study

included only men

which limits

generalizability. 
Colsher \& $\quad N=1768$ (581 males,

Wallace 1187 females) drawn from

(1991) Iowa Rural Health Study, U.S.

- age $65+$ years

- began in 1981

Cournot et $\quad N=2223$ drawn from

al. (2006) Vieillissment et Sante au

Travail (aging and health at work; VISAT) Study,

French.

- age at baseline from 32

to 62 years

- baseline in 1996; follow-

up in 2001
6 years

- Modified version of

Pfeiffer`s short portable

mental status questionnaire

- Memory (Word list)

- A measure of self-related

memory/metamemory (in-

person interviews)

5 years

- Word-list learning (four

recalls)

- Digit Symbol

Substitution Test

- Selective attention test
- Decrements of - Baseline basic

free recall of a

word list over 6

years. emographic variables

(age/gender/education)

predicted decline in

memory

- Lower levels of

educational

attainment were

predictive of more

rapid declines on

the mental status

examination and

recall memory tes

among women.

- Baseline basic

demographic variables

(age/gender/education)

- Clinical measures

(height, weight, blood

pressure, heart rate

measurements)
- Higher BMI at

baseline was

associated with a

higher cognitive

decline in word-list

learning.

- No significan

association was

found between

changes in BMI

and cognitive

function.
Strengths:

- Large population-

based sample

Limitations:

- The memory

performance tasks

used were not

clinical memory

tests, their clinical

and functional

correlations have

not been fully

explored.

Strengths:

- Large population-

based sample

Limitations:

- The functional

significance of

cognitive changes

in this sample was

difficult to assess

because functional

scales used in

elderly people were

not adapted to the

healthy working

population of this

sample. 
Furuäng et • N=211 elderly men from

al. (2013) a cohort of the population

study "Men born in 1914",

Malmö, Sweden

- age at baseline 68 years

- began in 1968

$\begin{array}{lll}14 \text { years } & \bullet \text { Test of Synonyms } & \bullet \text { Decline in } \\ & \bullet \text { Block Design } & \\ & \bullet \text { Digit Symbol } & \\ & \text { Substitution test } & \\ & \bullet \text { Benton Visual Retention } & \\ & \text { Test }\end{array}$

$\begin{array}{lll}\text { - Baseline basic } & \text { • Subjects with } & \text { Strengths: } \\ \text { demographic variables } & \text { enlarged left } & \bullet \text { Long 14-year } \\ \text { (age/gender/education) } & \text { ventricular internal } & \text { follow-up } \\ \text { - Left ventricular } & \text { dimension in } & \text { Limitations: } \\ \text { internal dimension in } & \text { diastole at age 68 } & \text { • High loss to } \\ \text { diastole } & \text { had poorer results } & \text { follow-up, which } \\ \text { - Cerebral blood flow } & \text { on verbal and } & \text { limits } \\ \text { - BMI } & \text { visuospatial tests in } & \text { generalizability. } \\ \text { - Ankle-brachial } & \text { follow-up. } & \bullet \text { The study } \\ \text { pressure index } & & \text { included only men } \\ & & \text { which limits } \\ & & \text { generalizability. }\end{array}$


Giambra $\bullet N=1721$ (1163 males,

et al. 558 females) from the

(1995)

Baltimore Longitudinal Study of Aging (BLSA)

U.S.

- age 17 to 102 years

- began in 1958
28 years - Immediate visual memory (Benton Visual

Retention Test)

- Crystallized intelligence

(Wechsler Adult

Intelligence Scale (WAIS),

Vocabulary subtest)
- Decline on

immediate

visual memory

from 6 to 25

years of follow-

up for men and

over 6 years

follow-up for

women between

65-74-years old

subjects.
- Baseline basic

demographic variables

(age/gender/education)
- Higher age

redicted decline in

memory

(longitudinally,

decrement of

cognition did not

reach a magnitude

sufficient to be

significant until

after 64 years).
Strengths:

- Large, well-

characterized

sample

- Use of combined

longitudinal and

cross-sectional data

Limitations:

- The sample

consists only of

very highly

educated

participants $(12$ -

17 or more years of

education), which

may limit the

generalizability of

the findings.

- High drop-out

percentages

between 1958 and

1986 :

$53 \%$ at the second

testing;

$79 \%$ at the third

testing (all females drop out);

$85 \%$ at the fourth

testing (only males

participated);

$93 \%$ at the fifth

testing (only males

participated) 
Glynn et

al. (2004)

- $N=2068$ drawn from the

East Boston component of

the Established

Populations for the

Epidemiologic Study of

the Elderly (EPESE) and

the Hypertension

Detection and Follow-Up

Program (HDFP)

- age 65 to 102 years

- EPESE baseline between

1982-1983; (HDFP)

follow-up between 1973 -

1974
6 years - Short Portable Mental

Status Questionnaire

- East Boston Memory

Test

Cognitive

decline over

time.

ne basic

emographic variables

(age/gender/education)

- Blood pressure
- There was little

vidence for an

effect of blood

pressure on change

in cognitive

function with either

est, or for an effect

on level of

on the memory

test.

- Longitudinal

population-based

- Large, well-

characterized

sample

Limitations:

- Crude cognitive

measures 
Hahn \&

Lachman

- $N=103$ (44\% females)

from the Midlife in the

United States study

(MIDUS), who also

participated in a satellite

Boston Longitudinal Study

(BOLOS), Boston, U.S.

- average age at follow-up

59 years

- began between 1995 an

1996; follow-up between

2004 and 2006
10 years $\bullet$ Working memory factor included tests of forward and backwards digit span and serial sevens (counting backwards by subtracting sevens).
- Decline in memory.
- Baseline basic

demographic variables

(age/gender/education)

- Functional health (by

asking participants

whether their health

limits them in daily

activities

- General perceived

control (was measured

as the average of 12

item inventory

assessing of beliefs

about control, persona

mastery, and perceived

constraint)
- Participants who

older, had lower

education, lower

general perceived

control, and higher

initial working

memory span at

Time 1 were more

likely to experience

greater memory

decline.

.

,

\section{Strengths: \\ - Longitudinal}

interdisciplinary

study

Limitations:

- Measure of

cognitive change

focused on tasks of

working memory,

rather than other

cognitive domains

or other aspects of

cognition.

- Measure of

working memory

was not a pure

measure of working

memory. 


\begin{tabular}{|c|c|c|c|c|c|c|c|}
\hline $\begin{array}{l}\text { Johansson } \\
\text { et al. } \\
(2004)\end{array}$ & $\begin{array}{l}-N=507 \text { (178 males, } 329 \\
\text { females) drawn from the } \\
\text { ongoing longitudinal } \\
\text { study, } \\
\text { "Origins of Variance in the } \\
\text { Old-Old" (OCTO Twin } \\
\text { Study), Sweden } \\
\text { - age at baseline } 80 \text { years } \\
\text { and older } \\
\text { - baseline between 1991- } \\
\text { 1993; follow-up in 2, } 4 \\
\text { and } 6 \text { years }\end{array}$ & 6 years & $\begin{array}{l}\text { - WAIS (General } \\
\text { knowledge; Synonyms } \\
\text { test; Digit-Symbol } \\
\text { Substitution Test; Digit } \\
\text { Span Forward and } \\
\text { Backward Test) } \\
\text { - WMS (The Prose Recall } \\
\text { test) } \\
\text { - The Figure Logic task } \\
\text { - Koh's Block Design } \\
\text { Test }\end{array}$ & $\begin{array}{l}\text { - Cognitive } \\
\text { decline over } \\
\text { time. }\end{array}$ & $\begin{array}{l}\text { - Baseline basic } \\
\text { demographic variables } \\
\text { (age/gender/education) } \\
\text { - Marital status } \\
\text { - Housing }\end{array}$ & $\begin{array}{l}\text { - Chronological } \\
\text { age and time to } \\
\text { death were } \\
\text { consistent } \\
\text { predictors of } \\
\text { decline in measures } \\
\text { of memory, } \\
\text { reasoning, speed, } \\
\text { and verbal abilities. }\end{array}$ & $\begin{array}{l}\text { Strengths: } \\
\text { - Longitudinal } \\
\text { interdisciplinary } \\
\text { study } \\
\text { - Large, well- } \\
\text { characterized } \\
\text { sample of } \\
\text { monozygotic and } \\
\text { same-sex } \\
\text { dizygotic twin pairs } \\
\text { Limitations: } \\
\text { - High loss to } \\
\text { follow-up, which } \\
\text { limits } \\
\text { generalizability. }\end{array}$ \\
\hline
\end{tabular}


Johnson et $\quad N=717$ from the registers

al. (2010)

of 10 general medical

practices

located in diverse

geographic and

sociodemographic areas

throughout the city of

Edinburgh, UK

- age at baseline $55-74$

years

baseline in 1987; follow-

up in 5 and 12 years
15 years $\bullet$ The National Adult

Reading Test (NART)

- Logical Memory

- Raven's Progressive

- Matrices

- Verbal Fluency

- Digit Symbol
- Cognitive

function

declined 0.04

standard

deviation per

year over the

period between

cognitive

assessments.
- Covariates (e.g.

age/gender)

- The ankle-brachial

index $(\mathrm{ABI})$
- ABI was not

associated with

change in cognitive

function.

- None of the

covariates had any

significant effect

on cognitive

change.
Strengths:

- Longitudinal

interdisciplinary

study

- Large, well-

characterized

sample

- Long 15-year

follow-up

Limitations:

- High loss to

follow-up, which

limits

generalizability. 


$\begin{array}{ll}\begin{array}{l}\text { Kobayashi } \\ \text { et al. }\end{array} & \bullet N=76 \text { (46 males, } 30 \\ (2014) & \text { females) non-psychotic, } \\ & \text { general population } \\ & \text { subjects drawn from the } \\ & \text { Northern Finland Birth } \\ & \text { Cohort } 1966 \text { Study, } \\ & \text { Finland } \\ & \bullet \text { age } 34 \text { years at first } \\ \text { cognitive assessment in } & \\ & 1999-2001 \\ & \bullet \text { age } 43 \text { years at second } \\ & \text { cognitive assessment in } \\ & 2008-2010 \\ & \bullet \text { began between 1999 - } \\ & 2001 ; \text { follow-up between } \\ & 2008 \text { - 2010 }\end{array}$

9 years

- Executive function

(Abstraction, Inhibition,

and Working Memory,

AIM)

- Visual learning and

memory(Visual Object

Learning, VOLT)

- Verbal Learning

(California Verbal

Learning Test, CVLT)
- Cognition was
found to stay
constant. was first able to stand
without support
- Developmental data at the age of 1 year of the infant when he/she<smiles>C1CCC2(CC1)CCCC2</smiles>

\begin{tabular}{|c|c|c|}
\hline 12 years & $\begin{array}{l}\text { - Verbal processing speed } \\
\text { - Working memory } \\
\text { - Reasoning, episodic } \\
\text { memory } \\
\text { - Semantic memory }\end{array}$ & $\begin{array}{l}\text { - Age-related } \\
\text { cognitive } \\
\text { decline. }\end{array}$ \\
\hline
\end{tabular}

- Biological age - Chronological age
MacDonal $\bullet N=125$ drawn from the d et al. (2004)

Victoria Longitudinal

Study (VLS), Canada
- age between 67 and 95

years

- baseline in the late

1980s; follow-up in 3-year intervals
- No significant association between age of learning to stand and change in cognition.
Strengths:

- Long 9-year

follow-up

- AIM task used in

this study is

associated with

adult brain

development, thus

it could be

especially sensitive

to cognitive change.

Limitations:

- The modest

number of subjects

- Crude cognitive

measures (i.e. only

one variable from

CVLT)

$\begin{array}{ll}\text { - Biological age } & \text { Strengths: } \\ \text { predicted actual } & \text { • Large population- } \\ \text { cognitive change } & \text { based cohort study } \\ \text { (decline) } & \text { • Long 12-year } \\ \text { independent of } & \text { follow up } \\ \text { chronological age. } & \text { Limitations: } \\ & \text { • High loss to } \\ & \text { follow-up, which } \\ & \text { limits } \\ & \text { generalizability. }\end{array}$


Matthews

et al.

(2012)
- $N=13,004$ drawn from the Medical Research

Council Cognitive

Function and Ageing

Study (MRC CFAS) from

six centres in England and

Wales

- age between 65 years

and over

- began in 1989; follow-up

in 2-, 6- and 10-year

intervals

\section{0 years - Mini-Mental State \\ Examination (MMSE) \\ - Age-related
cognitive
decline.}

- Baseline basic

demographic variables

(age/gender/education)

- Occupation-based

social class
- Women show

greater change in

MMSE scores with

age than men.

- Lower education

level and manual

work show greate

change in MMSE

scores with age.
Strengths:

- Large multi-

centre population-

based cohort study

- Long 10-year

follow up

Limitations:

- Crude cognitive

measures

- MMSE may be

relatively

insensitive to

differential patterns

of change in

cognitive ability. 


\begin{tabular}{|c|c|c|c|c|c|c|c|}
\hline $\begin{array}{l}\text { Muniz- } \\
\text { Terrera et } \\
\text { al. (2009) }\end{array}$ & $\begin{array}{l}-N=2053 \text { ( } 65 \% \text { females) } \\
\text { drawn from the Cambridge } \\
\text { City over } 75 \text { s Cohort } \\
\text { Study, UK } \\
\text { - age } 75+\text { years } \\
\text { - baseline in } 1985 \text {; follow- } \\
\text { up in } 2,7 \text { and } 9 \text { years }\end{array}$ & 9 years & $\begin{array}{l}\text { - Mini-Mental State } \\
\text { Examination (MMSE) }\end{array}$ & $\begin{array}{l}\text { - Age-related } \\
\text { cognitive } \\
\text { decline as } \\
\text { measured by the } \\
\text { MMSE. }\end{array}$ & $\begin{array}{l}\text { - Social class } \\
\text { - Education (the } \\
\text { average age at which } \\
\text { participants left } \\
\text { school) } \\
\text { - Information about } \\
\text { activities of daily } \\
\text { living }\end{array}$ & $\begin{array}{l}\text { - Women and } \\
\text { participants with } \\
\text { better mobility } \\
\text { were found to } \\
\text { experience a } \\
\text { slower decline with } \\
\text { age than men and } \\
\text { participants with } \\
\text { poorer mobility. }\end{array}$ & $\begin{array}{l}\text { Strengths: } \\
\text { - Large population- } \\
\text { based cohort study } \\
\text { - Long 9-year } \\
\text { follow up } \\
\text { Limitations: } \\
\text { - High loss to } \\
\text { follow-up, which } \\
\text { limits } \\
\text { generalizability. } \\
\text { - Crude cognitive } \\
\text { measures } \\
\text { - MMSE may be } \\
\text { relatively } \\
\text { insensitive to } \\
\text { differential patterns } \\
\text { of decline and } \\
\text { therefore significant } \\
\text { effects may not } \\
\text { emerge. }\end{array}$ \\
\hline $\begin{array}{l}\text { Nguyen et } \\
\text { al. (2002) }\end{array}$ & $\begin{array}{l}-N=1759 \text { ( } 65 \% \text { females) } \\
\text { drawn from the Hispanic } \\
\text { Established Population for } \\
\text { the Epidemiological Study } \\
\text { of the Elderly (Hispanic } \\
\text { EPESE), U.S. } \\
\text { - age } 65+\text { years } \\
\text { - baseline in 1993/1994; } \\
\text { follow-up in 1998/1999 }\end{array}$ & 5 years & $\begin{array}{l}\text { - Mini-Mental State } \\
\text { Examination (MMSE) }\end{array}$ & $\begin{array}{l}\text { - Cognitive } \\
\text { decline as } \\
\text { measured by the } \\
\text { MMSE. }\end{array}$ & $\begin{array}{l}\text { - Baseline basic } \\
\text { demographic variables } \\
\text { (age/gender/education) } \\
\text { - Marital status } \\
\text { - Household } \\
\text { - Diabetes/stroke/visio } \\
\text { n impairment }\end{array}$ & $\begin{array}{l}\text { - Age, education, } \\
\text { marital status, and } \\
\text { household } \\
\text { predicted actual } \\
\text { cognitive change } \\
\text { (decline). }\end{array}$ & $\begin{array}{l}\text { Strengths: } \\
\text { - Large population- } \\
\text { based cohort study } \\
\text { Limitations: } \\
\text { - MMSE may be } \\
\text { relatively } \\
\text { insensitive to } \\
\text { differential patterns } \\
\text { of decline and } \\
\text { therefore significant } \\
\text { effects may not } \\
\text { emerge. }\end{array}$ \\
\hline
\end{tabular}


Osler $e t$

al. (2013)

- $N=11532$ men drawn

rom the Danish person

identification system,

Copenhagen, Denmark

- cognitive assessments at ages 12, 18 and 57 years

- began in 1965; follow-up

in 6 and 45 years

45

$\begin{array}{lll}45 \text { years } & \text { From the school } & \bullet \text { Decline in } \\ \text { questionnaire in 1965: } & \text { cognitive } \\ \text { • Härnquist test battery } & \text { function } \\ \text { (three subtests with } & \text { between } 18 \text { and } \\ \text { geometric figures, number } & \text { 57 years. } \\ \text { series and verbal } & \\ \text { analogies) } & \\ \text { At 45-follow-up: } & \\ \text { - Intelligenz-Struktur-Test } & \\ \text { (sentence completion, } & \\ \text { verbal analogies and } & \\ \text { number series) } & \end{array}$

- Baseline basic

demographic variables

(age/gender/education)

- Impact of birth

characteristics

- Father's

occupational social

class

- Mother's age,

marital status at the

time of delivery and

birth weight

- Childhood activities

- Social class

- Having an

unskilled father at

birth, low

education, few

intellectual and

many social

activities in

childhood as well

as low adult social

class were

associated with

decline in cognitive

function.
Strengths:

- Large population-

based cohort study

- Long 45-year

follow up

Limitations:

- The study

included only men,

which limits

generalizability.

- Information on

cognitive function

at age 12 years was

only available for

7906 of the cohort

members.

- Only one-third of

those invited to the

45-years follow-up

participated. 
Payne et $\quad$ N=698 drawn from the

al. (2014) Advanced Cognitive

Training for Independent and Vital Elderly

(ACTIVE), U.S.

- mean baseline age 73.6 years

- baseline between 1999.

2001; follow-up period

over 10 years
10 years $\quad$ Paragraph Recall task

from the Rivermead

Behavioral Memory

Test, version 2 (spoken

discoure memory)

- Letter Sets, Letter Series and Word

Series tasks from the

Schaie-Thurstone Adult

Mental Ability Test

(inductive reasoning)

- Kit of

Factor-Referenced

Cognitive Tests (verbal

ability)
- Although

there was a

significant

heterogeneity in

the ran-

dom slopes for

SDM, verbal

ability and

reasoning,

annual decline

in these

variables was

not statistically

significant after

adjustment for

covariates.
- Baseline basic

demographic variables

(age/gender/education/

race)

- Self-reported health

status

- Baseline

psychomotor speed, as

measured by a

composite of

- The Digit Symbol

Substitution Test, Digit

Symbols Copy and

Useful Field of View

(UFOV) task

- Baseline auditory

episodic memory, as

measured by the

Auditory Verba

Learning Test
- Only age at

baseline uniquely

predicted

longitudinal

changes in spoken

discourse memory,

such that declines

ccelerated with

greater age.

(1)


Richards

et al.

(2004)
- $N=2058$ (1004 males,

1054 females) drawn from

the National Survey of

Health and Development

(NSHD), a Birth Cohort

1946 Study, UK

- age 53 years

- began in 1999

38
38 years At 15 years cohort:
- Verbal and non-verbal
ability (Heim AH4 test)
- Watts-Vernon reading
test

At 43 years cohort:

- Memory (a three trial 15

item word list)

- Speed and concentration

(timed letter search)

At 53 years cohort:

- Memory (a three trial 15

item word list)

- Speed and concentration

(timed letter search)

- National adult reading

test (NART)
- Decline in

memory.

- Baseline basic

demographic variables

(age/gender/education)

- Occupational social

class
- Increasing

attainment was

associated with

slower decline in

memory

independent of

ability in

childhood.
Strengths:

- Availability of

measured ability in

childhood and data

on a range of

potential

confounders and

the use of repeated

cognitive measures

in mid-life

Limitations:

- High loss to

follow-up, which

limits

generalizability

- Repeated

measures were

obtained for only

two cognitive tasks,

so there was no

possibility to

determine whether

the association

between early

ability and

cognitive decline is

general or confined

to specific

cognitive domains. 
Schaie

(1994)

- $N=5000$ drawn from the

Seattle Longitudinal

Study, Seattle,

Washington, U.S.

- average age in 199153

years

- began between 1956 and 1991 7-year

follow-

up for

the

longitudi

nal data

Total 35

years

during

six

testing

cycles:

1956

1963 ,

1970 ,

1977

1984

1991

Sturman et al. (2008)

\section{Average}

follow-
=3,885 (1516 males, 2369 females) drawn from the Chicago Health and Aging Project (CHAP), U.S.

- age 65 and older (mean age 73.8 years)

- conducted from 1993 to 2003; follow-up twice at approximately 3 -years intervals
- Verbal meaning, space, reasoning, number, and word fluency, perceptual speed

up of

6.4 years

functioning (MMSE)

- Episodic memory (East

Boston Tests of Im-

mediate Memory and Delay

Recall)

- Perceptual speed

(Symbol

Digit Modalities Test)
- At least

modest gain for

all abilities from

young

dulthood to age

60.

- Reliable

average

decrement for

all abilities by

age 67 years.

global cognition

over time.

- Baseline basic

demographic variables

(age/gender/education/

race)

- Body mass index

(BMI)

- Baseline basic

ographic variables

-

activities, travel

environment

- Scale for measuring

participant's subjective

assessment of ability

cycles

Health history records and social interactions,

- In a mixed model Strengths: adjusted for age,

gender, race, and

education, higher

BMI was

associated with less

cognitive decline in

both black and

non-black subjects.
- Large population-

based study

- Relatively long

follow-up

Limitations:

- Height was self-

reported and

therefore may not

be accurate,

especially in older

adults who may

experience age or

disease related loss

of height. 
Zelinski \& $\quad N=106$ (48 males, 58

Burnight

(1997)

females) drawn from the

Health Plan, an Health

Maintenance Organization

with most members Long

Beach and Orange County,

California, U.S

- age $30-36$ and $55-81$

at baseline

- began in 1978; follow-up

in 1994
16 years

- Verbal memory

(immediate written: free

recall of 20 nouns, 227-

word essay, 20-min

delayed recognition of the

words from list including

the original 20 words)

- Intelligence scores from

the STAMAT (Letter

Series, Word Series,

Figure Rotation, Object

Rotation, Recognition

vocabulary)
- Reliable

decline in list

and text recall,

reasoning and

space after age

55 .

eline basic

demographic variables

(age/gender/education)

Higher age

Strengths:

- Long 16-year-

list and text recall

reasoning and

follow-up and

large population-

based study

- Used both cross-

sectional and

longitudinal data 
Table 2. Representativeness and comparison of the sample.

\begin{tabular}{|c|c|c|c|}
\hline & $\begin{array}{l}\text { Participants } \\
\qquad \mathrm{N}=75\end{array}$ & $\begin{array}{l}\text { Non-participants } \\
\qquad \mathrm{N}=10524\end{array}$ & $\mathrm{P}$ \\
\hline \multicolumn{4}{|l|}{ Comparison with the NFBC 1966} \\
\hline Gender, n $(\%)$ & $\mathrm{n}=75$ & $\mathrm{n}=10522$ & $0.08^{1}$ \\
\hline Males & $46(61.3 \%)$ & $5359(50.9 \%)$ & \\
\hline Females & $29(38.7 \%)$ & $5165(49.1 \%)$ & \\
\hline Primary school marks, mean (SD) & $\mathrm{n}=74$ & $\mathrm{n}=10290$ & \\
\hline All subjects & $7.61(0.89)$ & $7.56(0.95)$ & $0.66^{2}$ \\
\hline Theoretical & $7.43(1.07)$ & $7.39(1.11)$ & $0.75^{2}$ \\
\hline Practical & $8.02(0.61)$ & $7.95(0.73)$ & $0.32^{2}$ \\
\hline Education by 1997 & $\mathrm{n}=75$ & $\mathrm{n}=10512$ & $0.021^{1}$ \\
\hline 9 years or less & $3(4.0 \%)$ & $1588(15.1 \%)$ & \\
\hline 10 to 12 years & $48(64.0 \%)$ & $6253(59.5 \%)$ & \\
\hline Over 12 years & $24(32.0 \%)$ & $2671(25.4 \%)$ & \\
\hline \multicolumn{4}{|l|}{ Comparison with the baseline participants } \\
\hline Gender, n $(\%)$ & $\mathrm{n}=75$ & $\mathrm{n}=27$ & $>0.99^{1}$ \\
\hline Males & $46(61.3 \%)$ & $16(59.3 \%)$ & \\
\hline Females & $29(38.7 \%)$ & $11(40.7 \%)$ & \\
\hline Vocational education at baseline $^{3}, \mathrm{n}(\%)$ & $\mathrm{n}=75$ & $\mathrm{n}=27$ & $0.48^{1}$ \\
\hline Low & $31(41.3 \%)$ & $9(33.3 \%)$ & \\
\hline Middle & $15(20.0 \%)$ & $4(14.8 \%)$ & \\
\hline High & $29(38.7 \%)$ & $14(51.9 \%)$ & \\
\hline Cognitive measures, mean (SD) & $\mathrm{n}=70-75$ & $\mathrm{n}=26$ & \\
\hline \multicolumn{4}{|l|}{ CVLT } \\
\hline Immediate free recall & $59.7(7.3)$ & $60.0(8.6)$ & $0.86^{2}$ \\
\hline Short delay, free recall & $13.1(2.3)$ & $13.0(2.5)$ & $0.98^{2}$ \\
\hline Long delay, free recall & $13.6(2.2)$ & $14.0(2.5)$ & $0.49^{2}$ \\
\hline VOLT & $68.6(5.4)$ & $68.4(4.8)$ & $0.90^{2}$ \\
\hline AIM, abstraction without memory & $24.1(2.5)$ & $24.7(2.2)$ & $0.32^{2}$ \\
\hline AIM, abstraction with memory & $23.6(3.4)$ & $23.5(3.2)$ & $0.91^{2}$ \\
\hline
\end{tabular}

NFBC 1966 = Northern Finland Birth Cohort 1966. SD = standard deviation.

CVLT $=$ California Verbal Learning Test. VOLT $=$ Visual Object Learning Test. AIM = Abstraction Inhibition and Memory task.

Significance from ${ }^{1}$ chi square test or ${ }^{2}$ independent samples t-test.

${ }^{3}$ Low $=$ comprehensive school with lower level of vocational education; middle $=$ comprehensive school with higher level of vocational education or upper secondary school with lower level of vocational education; and high = upper secondary school with higher level of vocational education. 
Table 3. Characteristics of the sample at baseline at the age of 34 years $(n=75)$.

\begin{tabular}{lr}
\hline Characteristic & Baseline \\
\hline Follow-up time, years, mean (SD) & $8.5(0.7)$ \\
Gender (n, \%) & $29(39 \%)$ \\
$\quad$ Females & $46(61 \%)$
\end{tabular}

Primary school marks, mean (SD)

All subjects

Theoretical subjects

Practical subjects

Vocational education, $\mathrm{n}(\%)^{1}$

Low

Middle

High

Social class based on occupation, $\mathrm{n}(\%)^{2}$

Low (Employee, student, or unemployed)

Middle (Official level employee)

High (Managerial employee)

Marital status, n (\%)

Not married

Married

Children, n (\%)

No

Yes

Body mass index, n (\%)

$<25 \mathrm{~kg} / \mathrm{m}^{2}$
$\geq 25 \mathrm{~kg} / \mathrm{m}^{2}$

At age 34 years, mean (SD)

Change from 34 to 43 years, mean (SD)

Psychiatric diagnosis ${ }^{3}$

Somatic illnesses ${ }^{4}$

$7(9 \%)$

$\mathrm{SD}=$ standard deviation.

${ }^{1}$ Low $=$ comprehensive school with lower level of vocational education; middle = comprehensive school with higher level of vocational education/upper secondary school with lower level of vocational education; and high = upper secondary school with higher level of vocational education.

${ }^{2}$ Based on the educational level, entrepreneurs were combined with managerial employees $(n=2)$ or official level employees $(n=2)$.

${ }^{3}$ Specific diagnoses: depression $(n=1)$, panic disorder $(n=1)$, depression and panic disorder $(n=1)$. Diagnoses are based on SCID I interview performed at baseline (Haapea et al. 2007).

${ }^{4}$ Somatic illnesses: hypothyreosis $(n=1)$, spondylarthritis ancylopoetica $(n=1)$, asthma $(n=1)$, asthma, migraine $(n=1)$, asthma, hypothyreosis, keliakia $(n=1)$, epilepsy, no medication nor symptoms since age 16 years $(n=1)$, lumbar disc prolapse operated years ago $(n=1)$. Information on illnesses is based on interview at baseline (Haapea et al. 2007). 
Table 4. Original scores of CVLT, VOLT and AIM at baseline (age 34) and follow-up (age 43), and change of cognitive performance between baseline and follow-up.

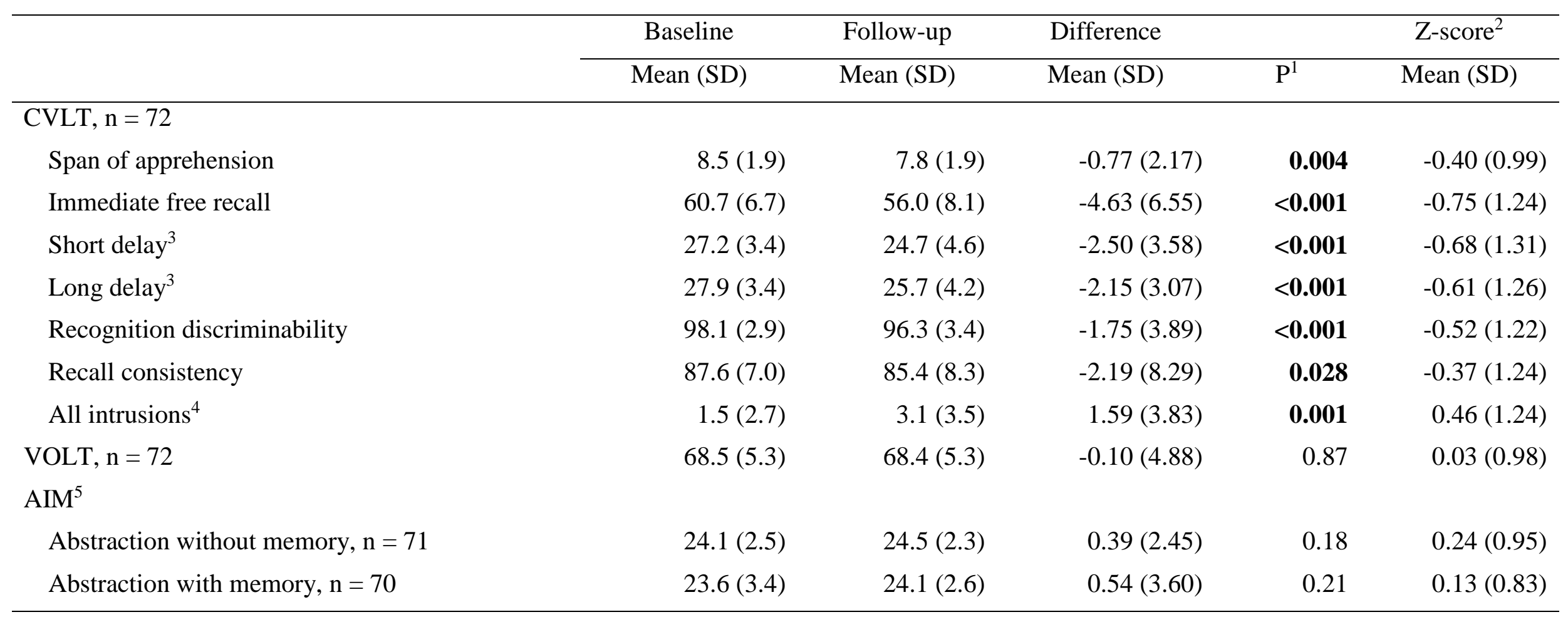

CVLT $=$ California Verbal Learning Test, VOLT $=$ Visual Object Leaning Test, AIM = Abstraction Inhibition and Memory task.

${ }^{1}$ Paired samples t-test; bolded p-values are statistically significant after the Benjamini-Hochberg correction.

${ }^{2}$ Standardized follow-up score of cognitive performance.

${ }^{3}$ Free and qued recalls summed.

${ }^{4}$ Intrusions for all trials throughout the CVLT summed.

${ }^{5}$ Scores less than half of the maximum are considered as below chance. Within AIM, 1 subject was excluded from Abstraction without memory and 1 subject from Abstraction without memory and with memory. 
Table 5. Statistically significant associations between continuous predictors and cross-sectional cognitive performance at baseline $(n=75)$.

\begin{tabular}{|c|c|c|c|c|}
\hline \multirow[b]{2}{*}{ Predictor } & \multirow[b]{2}{*}{ Cognitive measure } & \multicolumn{2}{|c|}{ Regression coefficients } & \multirow[b]{2}{*}{$\mathrm{P}$-value } \\
\hline & & $\begin{array}{l}\text { B (standard } \\
\text { error) }\end{array}$ & Beta & \\
\hline \multicolumn{5}{|l|}{ Gender } \\
\hline & Immediate free recall & $4.4(1.5)$ & 0.33 & 0.005 \\
\hline & Recall consistency & $4.2(1.6)$ & 0.30 & 0.009 \\
\hline & Intrusions & $1.4(0.6)$ & 0.26 & 0.028 \\
\hline & AIM, Abstraction with memory & $1.8(0.8)$ & 0.27 & 0.022 \\
\hline \multicolumn{5}{|c|}{$\begin{array}{l}\text { Primary school marks, } \\
\text { all subjects }\end{array}$} \\
\hline & Immediate free recall & $2.4(0.8)$ & 0.34 & 0.004 \\
\hline & Short delay & $1.0(0.4)$ & 0.28 & 0.016 \\
\hline & Long delay & $1.0(0.4)$ & 0.29 & 0.014 \\
\hline & Recall consistency & $3.2(0.8)$ & 0.43 & $<0.001$ \\
\hline & Intrusions & $0.8(0.3)$ & 0.28 & 0.017 \\
\hline & AIM, Abstraction with memory & $1.2(0.4)$ & 0.33 & 0.006 \\
\hline \multicolumn{5}{|c|}{$\begin{array}{l}\text { Primary school marks, } \\
\text { theoretical subjects }\end{array}$} \\
\hline & Immediate free recall & $1.8(0.7)$ & 0.31 & 0.009 \\
\hline & Short delay & $0.8(0.4)$ & 0.27 & 0.024 \\
\hline & Long delay & $0.8(0.4)$ & 0.27 & 0.024 \\
\hline & Recall consistency & $2.5(0.7)$ & 0.40 & 0.001 \\
\hline & Intrusions & $0.7(0.3)$ & 0.28 & 0.019 \\
\hline & AIM, Abstraction with memory & $1.0(0.4)$ & 0.31 & 0.008 \\
\hline \multicolumn{5}{|c|}{$\begin{array}{l}\text { Primary school marks, } \\
\text { practical subjects }\end{array}$} \\
\hline & Immediate free recall & $4.2(1.1)$ & 0.41 & $<0.001$ \\
\hline & Short delay & $1.7(0.6)$ & 0.33 & 0.005 \\
\hline & Long delay & $1.8(0.6)$ & 0.35 & 0.003 \\
\hline & Recall consistency & $5.3(1.1)$ & 0.49 & $<0.001$ \\
\hline & Intrusions & $1.1(0.5)$ & 0.26 & 0.029 \\
\hline & AIM, Abstraction with memory & $1.6(0.6)$ & 0.30 & 0.010 \\
\hline \multicolumn{5}{|c|}{ Vocational education } \\
\hline & Immediate free recall & $3.2(0.8)$ & 0.42 & $<0.001$ \\
\hline & Short delay & $1.4(0.4)$ & 0.36 & 0.002 \\
\hline & Long delay & $1.4(0.4)$ & 0.37 & 0.002 \\
\hline & Recall consistency & $4.0(0.8)$ & 0.51 & $<0.001$ \\
\hline & AIM, Abstraction with memory & $1.6(0.4)$ & 0.41 & $<0.001$ \\
\hline \multicolumn{5}{|c|}{ Occupational class } \\
\hline & Long delay & $1.0(0.5)$ & 0.25 & 0.036 \\
\hline & Recall consistency & $3.0(1.0)$ & 0.34 & 0.004 \\
\hline \multicolumn{5}{|l|}{ Children } \\
\hline & $\begin{array}{l}\text { AIM, Abstraction without } \\
\text { memory }\end{array}$ & $1.3(0.6)$ & 0.25 & 0.037 \\
\hline \multicolumn{5}{|l|}{ BMI } \\
\hline & Recognition discriminability & $-0.2(0.1)$ & -0.29 & 0.013 \\
\hline & $\begin{array}{l}\text { AIM, Abstraction without } \\
\text { memory }\end{array}$ & $-0.15(0.07)$ & -0.26 & 0.027 \\
\hline
\end{tabular}

$\mathrm{AIM}=$ Abstraction Inhibition and Memory task.

${ }^{1}$ Significance from linear regression analysis; bolded p-values are statistically significant after the

Benjamini-Hochberg correction. 
Table 6. Predictors of changes in CVLT, adjusted for the baseline cognitive performance and weighted by gender and education ( $\mathrm{n}=75$ ).

\begin{tabular}{|c|c|c|c|c|c|c|c|c|c|c|c|c|c|c|}
\hline & \multicolumn{2}{|c|}{$\begin{array}{c}\text { Span of } \\
\text { apprehension }\end{array}$} & \multicolumn{2}{|c|}{$\begin{array}{l}\text { Immediate free } \\
\text { recall }\end{array}$} & \multicolumn{2}{|c|}{ Short delay } & \multicolumn{2}{|c|}{ Long delay } & \multicolumn{2}{|c|}{$\begin{array}{c}\text { Recognition } \\
\text { discriminability }\end{array}$} & \multicolumn{2}{|c|}{$\begin{array}{c}\text { Recall } \\
\text { consistency }\end{array}$} & \multicolumn{2}{|c|}{ All intrusions } \\
\hline & Beta & P-value & Beta & P-value & Beta & P-value & Beta & P-value & Beta & $\mathrm{P}$-value & Beta & $\mathrm{P}$-value & Beta & P-value \\
\hline Gender & 0.28 & 0.004* & 0.35 & 0.003* & $\mathbf{0 . 3 5}$ & 0.003* & 0.20 & 0.097 & 0.16 & 0.12 & 0.16 & 0.15 & 0.12 & 0.29 \\
\hline \multicolumn{15}{|l|}{ Primary school marks } \\
\hline All subjects & 0.18 & 0.067 & 0.14 & 0.25 & 0.19 & 0.12 & 0.12 & 0.35 & -0.04 & 0.69 & -0.03 & 0.79 & 0.05 & 0.68 \\
\hline Theoretical subjects & 0.17 & 0.080 & 0.11 & 0.39 & 0.16 & 0.20 & 0.10 & 0.41 & -0.07 & 0.52 & -0.08 & 0.51 & 0.03 & 0.80 \\
\hline Practical subjects & 0.17 & 0.086 & 0.27 & 0.032 & 0.28 & 0.023 & 0.14 & 0.28 & 0.03 & 0.74 & 0.19 & 0.14 & 0.11 & 0.31 \\
\hline Vocational education & 0.14 & 0.15 & -0.05 & 0.71 & 0.09 & 0.46 & 0.04 & 0.77 & 0.11 & 0.29 & -0.12 & 0.36 & -0.002 & 0.98 \\
\hline Occupational class & -0.03 & 0.79 & -0.08 & 0.51 & 0.03 & 0.79 & -0.03 & 0.80 & -0.03 & 0.79 & -0.16 & 0.16 & 0.03 & 0.79 \\
\hline Marital status & -0.02 & 0.87 & -0.10 & 0.37 & 0.17 & 0.17 & 0.03 & 0.82 & 0.04 & 0.74 & 0.02 & 0.89 & -0.10 & 0.34 \\
\hline Children & 0.06 & 0.51 & 0.03 & 0.82 & 0.11 & 0.35 & 0.17 & 0.14 & 0.10 & 0.32 & 0.10 & 0.35 & -0.26 & 0.014 \\
\hline \multicolumn{15}{|l|}{ Body mass index } \\
\hline At age 34 years & -0.06 & 0.56 & -0.13 & 0.25 & 0.02 & 0.87 & 0.08 & 0.49 & 0.14 & 0.19 & -0.13 & 0.26 & -0.16 & 0.12 \\
\hline $\begin{array}{l}\text { Change from age } 34 \\
\text { to } 43 \text { years }\end{array}$ & -0.11 & 0.28 & -0.09 & 0.47 & -0.12 & 0.33 & -0.12 & 0.33 & -0.05 & 0.64 & 0.04 & 0.72 & 0.26 & 0.018 \\
\hline
\end{tabular}

CVLT $=$ California Verbal Learning Test.

Bolded p-values marked with an asterisk are statistically significant after the Benjamini-Hochberg correction. 
Table 7. Predictors of changes in VOLT and AIM, adjusted for baseline cognitive performance and weighted by gender and education $(n=75)$.

\begin{tabular}{|c|c|c|c|c|c|c|}
\hline & \multicolumn{2}{|c|}{ VOLT } & \multicolumn{2}{|c|}{$\begin{array}{l}\text { AIM, Abstraction without } \\
\text { memory }\end{array}$} & \multicolumn{2}{|c|}{$\begin{array}{l}\text { AIM, Abstraction with } \\
\text { memory }\end{array}$} \\
\hline & Beta & P-value & Beta & P-value & Beta & P-value \\
\hline Gender & $\begin{array}{c}-0.14 \\
\end{array}$ & 0.20 & -0.02 & 0.81 & -0.15 & 0.077 \\
\hline \multicolumn{7}{|l|}{ Primary school marks } \\
\hline All subjects & 0.33 & $0.002 *$ & 0.03 & 0.74 & 0.08 & 0.36 \\
\hline Theoretical subjects & 0.32 & $0.002 *$ & 0.04 & 0.73 & 0.09 & 0.34 \\
\hline Practical subjects & 0.30 & 0.004* & 0.01 & 0.95 & 0.05 & 0.59 \\
\hline Vocational education & 0.28 & 0.007 & 0.02 & 0.85 & 0.01 & 0.93 \\
\hline Occupational class & 0.31 & 0.003* & 0.03 & 0.76 & 0.08 & 0.36 \\
\hline Marital status & 0.11 & 0.29 & 0.18 & 0.069 & -0.15 & 0.083 \\
\hline Children & 0.01 & 0.94 & -0.09 & 0.42 & -0.21 & 0.012 \\
\hline \multicolumn{7}{|l|}{ Body mass index } \\
\hline At age 34 years & -0.20 & 0.053 & 0.07 & 0.48 & -0.14 & 0.11 \\
\hline $\begin{array}{l}\text { Change from age } 34 \\
\text { to } 43 \text { years }\end{array}$ & -0.01 & 0.91 & -0.19 & 0.072 & 0.08 & 0.34 \\
\hline
\end{tabular}

VOLT = Visual Object Learning Test. AIM = Abstraction Inhibition and Memory task.

Bolded p-values marked with an asterisk are statistically significant after the Benjamini-Hochberg correction. 